INSTITUTO DE PESQUISAS ENERGÉTICAS E NUCLEARES

Autarquia associada à Universidade de São Paulo

\title{
DETERMINAÇÃO DA TAXA DE DESINTEGRAÇÃO E DAS PROBABILIDADES DE EMISSÃO GAMA POR DECAIMENTO DO ${ }^{182} \mathrm{Ta}$
}

\section{ELIEZER ANTONIO DA SILVA}

Dissertação apresentada como parte dos requisitos para a obtenção do Grau de Mestre em Ciências na Área de Tecnologia Nuclear-Aplicações.

Orientadora:

Dra.Marina Fallone Koskinas

São Paulo 
Ao Antonio Batista da Silva, à Maria do Carmo da Silva e a Elisangela Ap. B. da Silva, pois tudo o que tenho e tudo o que sou é graças a minha família. 
“Na vida, não existe nada a temer, mas a entender".

\section{Marie Sklodowaska Curie}




\section{Agradecimentos:}

À Dra. Marina Fallone Koskinas, orientadora deste trabalho, pela oportunidade, apoio, compreensão, incentivo, paciência e dedicação durante todo o desenvolvimento desta dissertação;

Ao Dr. Mauro da Silva Dias, pelas valorosas sugestões, incentivo, paciência e apoio na realização deste trabalho;

À todos os professores do curso de pós-graduação, que contribuíram para a realização deste trabalho e à minha formação acadêmica;

Ao Físico Carlos Augusto Pires, irmão em ciência, pela amizade, sugestões, estímulo e companheirismo durante todas as etapas da realização deste trabalho;

Aos colegas Mauro Noriaki Takeda, Hélio Piuvezam Filho, Franco Brancaccio, Fábio de Toledo e Cláudio Domienikan, pela amizade, estímulo e colaboração;

Às colegas Ione M. Iamazaki, Denise Simões Moreira, Cláudia R. Ponge-Ferreira, Margareth Lika Onishi Tongu, pela amizade, estímulo e colaboração;

Ao Dr. Frederico Antonio Genezini pelas valorosas sugestões, apoio, estímulo e amizade durante todos estes anos de estudo na área da Física Nuclear;

Ao Instituto de Pesquisas Energéticas e Nucleares;

À minha família que sempre me apoiou e incentivou nos meus estudos;

Apesar deste trabalho ser de natureza científica e o pesquisador ser cético, agradeço também a Deus, pois nos eventos probabilísticos da minha vida era à ele que eu recorria. 
E à todos aqueles que diretamente ou indiretamente colaboraram na realização deste trabalho. 


\title{
DETERMINAÇÃO DA TAXA DE DESINTEGRAÇÃO E DAS PROBABILIDADES DE EMISSÃO GAMA POR DECAIMENTO DO ${ }^{182}$ Ta
}

\author{
ELIEZER ANTONIO DA SILVA
}

\section{RESUMO}

Neste trabalho foi desenvolvido o método para a padronização de fontes de ${ }^{182} \mathrm{Ta}$ produzidas no reator de pesquisas IEA-R1 do IPEN. O ${ }^{182} \mathrm{Ta}$ decai com uma meia-vida de 114 dias pelo decaimento $\beta^{-}$, populando os níveis excitados do ${ }^{182} \mathrm{~W}$. São emitidos raios gamas de várias energias entre $31 \mathrm{keV}$ e $264 \mathrm{keV}$ e entre $1001 \mathrm{keV}$ e $1453 \mathrm{keV}$. As medidas foram realizadas em um sistema de coincidência $4 \pi \beta-\gamma$ utilizando a técnica da extrapolação linear da eficiência. O sistema de coincidência é composto de um contador proporcional $4 \pi$ acoplado a um cristal de $\mathrm{NaI}(\mathrm{Tl})$. As medidas foram realizadas selecionando dois intervalos de energias na via gama, a fim de verificar a consistência dos resultados. Um cálculo utilizando o método de Monte Carlo que prevê o comportamento da atividade observada em função da eficiência do detector $4 \pi(\mathrm{PC})$ foi utilizado. Os resultados foram comparados com os valores experimentais. As probabilidades de emissão gama mais intensas do ${ }^{182} \mathrm{Ta}$ foram determinadas por meio de um espectrômetro gama de HPGe, a curva de eficiência do espectrômetro de germânio foi obtida por meio da utilização de fontes de ${ }^{152} \mathrm{Eu},{ }^{241} \mathrm{Am},{ }^{60} \mathrm{Co},{ }^{133} \mathrm{Ba}$ e ${ }^{166 \mathrm{~m}} \mathrm{Ho}$, padronizadas em sistema primário. As incertezas envolvidas nas medidas foram tratadas pela metodologia de covariância. Os resultados obtidos são concordantes dentro da incerteza experimental com valores encontrados na literatura. 


\title{
DETERMINATION OF THE DISINTEGRATION RATE AND GAMMA EMISSION PROBABILITIES PER DECAY OF ${ }^{182}$ TA
}

\author{
ELIEZER ANTONIO DA SILVA
}

\begin{abstract}
In this work the procedure developed for the standardization of ${ }^{182} \mathrm{Ta}$ sources produced by irradiation at the IPEN IEA-R1 research reactor is presented. The ${ }^{182} \mathrm{Ta}$ decays with a half-life of 114 days by $\beta^{-}$emission, populating the excited levels of ${ }^{182} \mathrm{~W}$. It emits gamma rays with several energies mainly between $31 \mathrm{keV}$ and $264 \mathrm{keV}$ and between $1001 \mathrm{keV}$ and $1453 \mathrm{keV}$. The measurements were performed in a $4 \pi \beta-\gamma$ coincidence system by using the extrapolation technique. The coincidence system is composed of a $4 \pi$ proportional counter coupled to a $\mathrm{NaI}(\mathrm{Tl})$ cristal. The measurements were undertaken selecting two windows in the $\gamma$-channel, in order to check the consistency of the results. A Monte Carlo calculation was performed in order to predict the behavior of the observed activity as a function of the $4 \pi \beta$ detector efficiency and the results were compared to experimental values. The most intense gamma-ray emission probabilities of ${ }^{182}$ Ta were determined by means of an HPGe gamma spectrometer, the germanium efficiency curve was obtained by using sources ${ }^{152} \mathrm{Eu}$, ${ }^{241} \mathrm{Am},{ }^{60} \mathrm{Co},{ }^{133} \mathrm{Ba}$ and ${ }^{166 \mathrm{~m}} \mathrm{Ho}$ standardized in a primary system. The uncertainties involved in the measurements were treated by the covariance methodology. The results obtained are in good agreement with the experimental uncertainty compared with literature values.
\end{abstract}




\section{SUMÁRIO}

Página

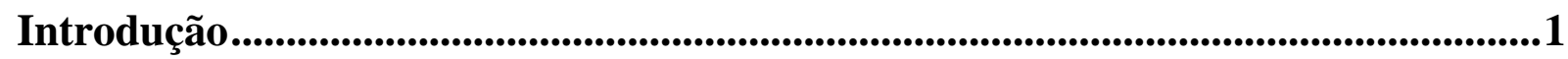

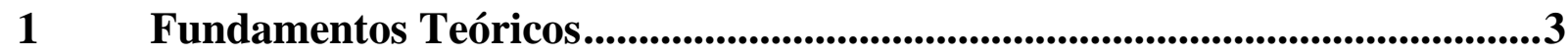

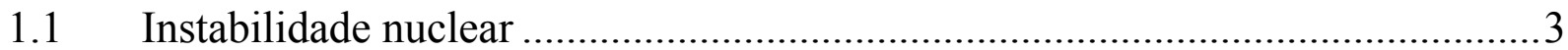

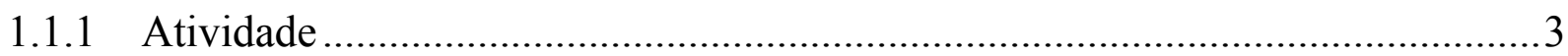

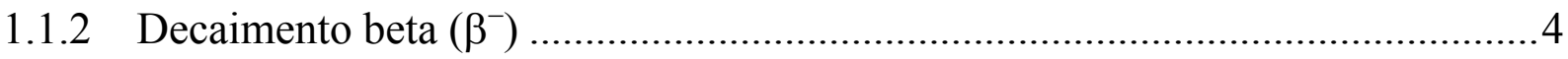

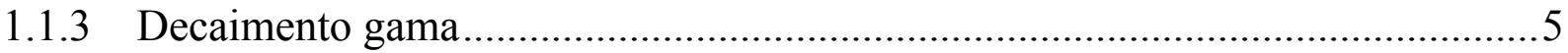

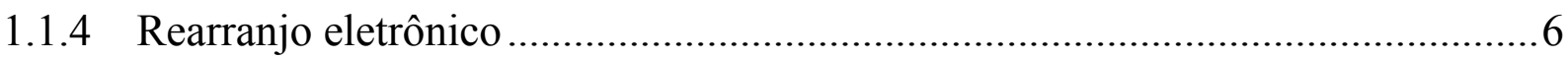

1.1.5 Interação das partículas beta com a matéria........................................................

1.1.6 Interação das radiações gama com a matéria ......................................................

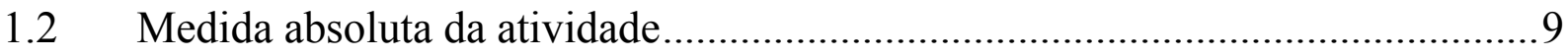

1.2.1 Técnica da extrapolação linear da eficiência .....................................................11

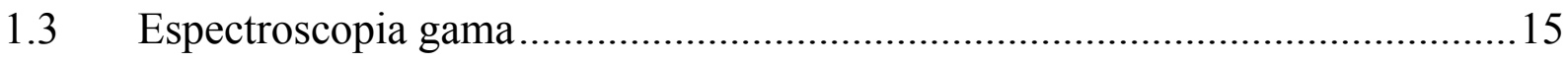

2 Padronização do ${ }^{182}$ Ta..........................................................................18

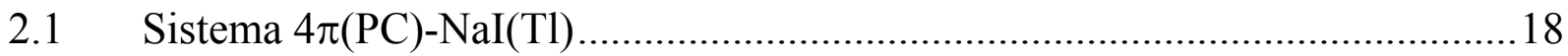

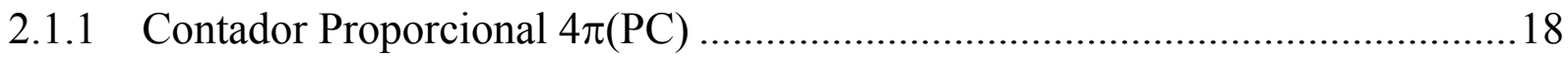

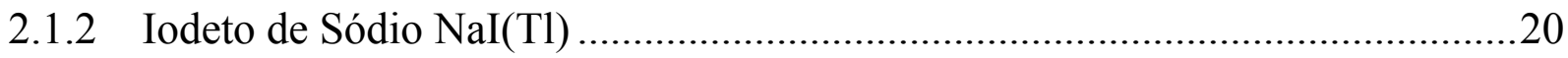

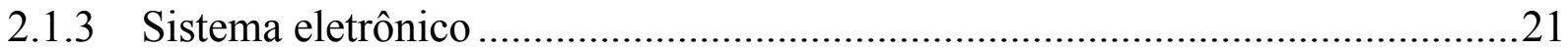

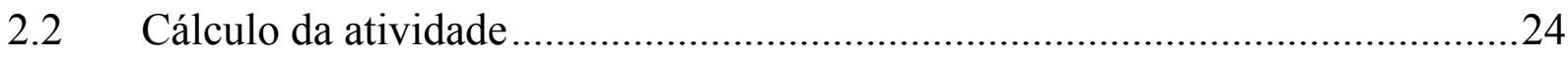

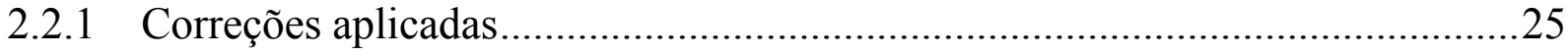

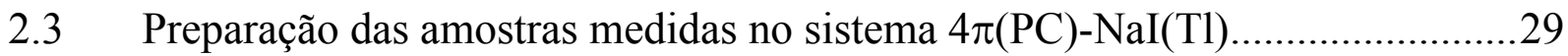

2.3.1 Preparação de substratos de Collodion .............................................................29

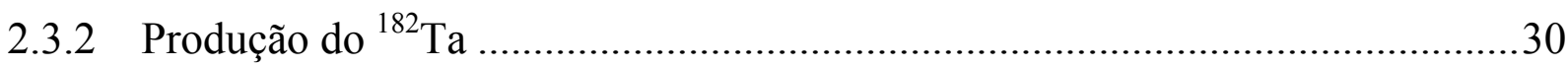

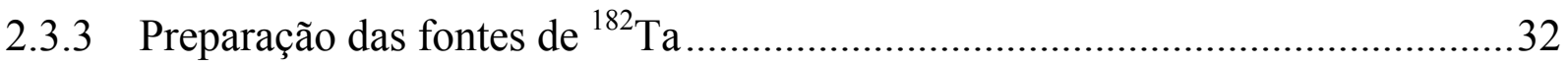

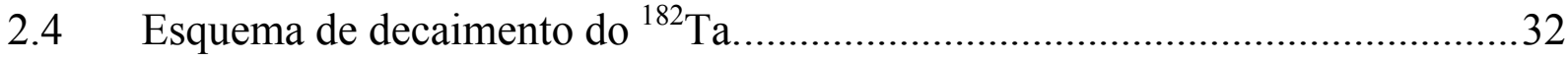

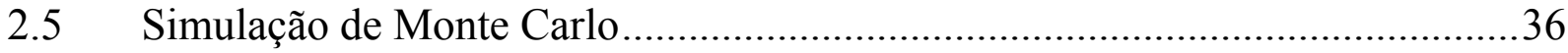

3 Determinação das probabilidades de emissão $\gamma$ por decaimento do ${ }^{182}$ Ta.. 41 
3.1 Detector de HPGe ou Germânio Intrínseco …….................................................

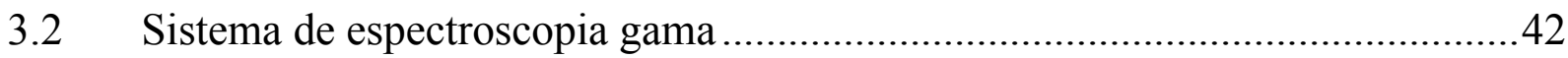

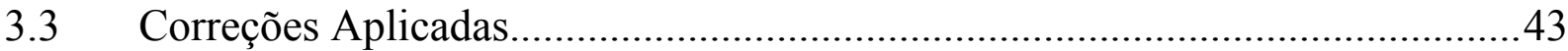

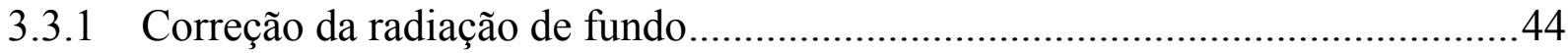

3.3.2 Correção para o efeito de auto-absorção, atenuação e geometria ........................45

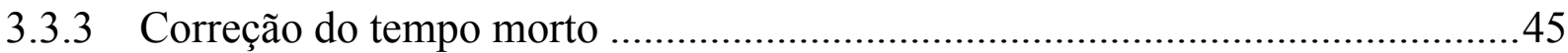

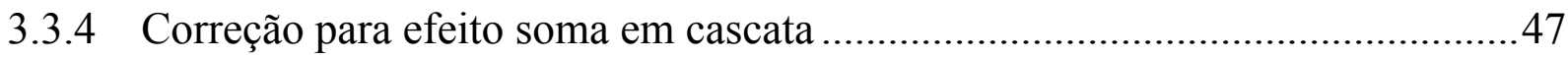

3.4 Calibração do espectrômetro HPGe ...................................................................49

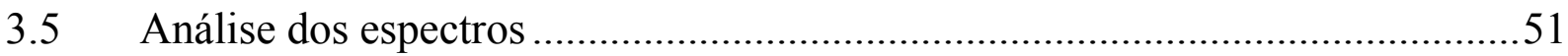

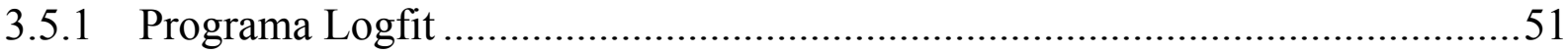

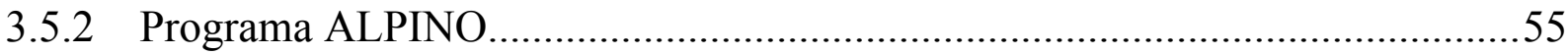

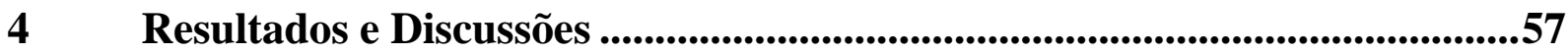

4.1 Medida no sistema $4 \pi \beta-\gamma$ pela técnica da extrapolação linear da eficiência ....57

4.1.1 Comparação dos resultados experimentais com a simulação de Monte Carlo ..64

4.2 Determinação das probabilidades de emissão gama por decaimento ..................66

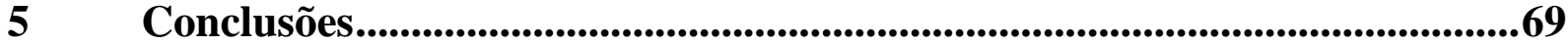

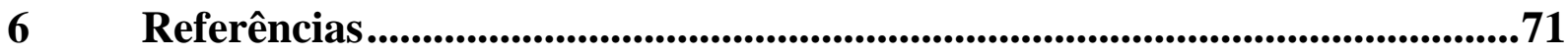




\section{INTRODUÇÃO}

O desenvolvimento da tecnologia nuclear tem-se mostrado cada vez mais necessário nos tempos atuais. Na área da saúde, na indústria e controle ambiental, esta tecnologia está presente em diversas situações destas atividades.

Para que o emprego desta tecnologia tenha êxito, um dos elementos essenciais é o uso das fontes radioativas com suas características conhecidas com boa exatidão, entre elas destaca-se a atividade e os parâmetros dos esquemas de decaimento como a probabilidade de emissão gama por decaimento e sua meia-vida.

O conhecimento destes fatores permite que os usuários ou experimentadores tenham resultados confiáveis e precisos e calibrem seus instrumentos com acurácia. Além disso, o conhecimento destes parâmetros auxilia na compreensão da estrutura nuclear.

Métodos absolutos ou primários são aqueles capazes de mensurar grandezas com boa precisão sem a necessidade de padrões. Em metrologia nuclear a determinação da atividade de uma fonte radioativa por um método primário é feita pela observação da taxa de desintegração ao decorrer do tempo, dispensando assim, diversos parâmetros nucleares e/ou parâmetros do sistema de calibração utilizado.

O método da coincidência é o método primário mais utilizado na padronização de diversos radionuclídeos emissores de dois tipos de radiação, neste método detectores específicos para cada tipo de radiação são empregados e os eventos coincidentes são detectados sem a necessidade do conhecimento prévio dos parâmetros do esquema de decaimento da fonte em questão e das eficiências do sistema utilizado.

O laboratório de Metrologia Nuclear do IPEN (LMN) desde a sua criação desenvolve métodos de padronização de radionuclídeos e medidas de probabilidades de 
emissão gama por decaimento utilizando sistemas de coincidência $4 \pi(\mathrm{PC})-\mathrm{NaI}(\mathrm{Tl})$ e espectrômetros gama ${ }^{[1,2]}$.

A seleção dos radionuclídeos a serem estudados baseia-se em suas aplicações práticas, isto é, radionuclídeos de uso em medicina nuclear ou que possam ser utilizados como padrões na calibração de espectrômetros.

Este trabalho tem por objetivo, o desenvolvimento do método de padronização do tântalo-182 ( ${ }^{182} \mathrm{Ta}$ ) pelo método da coincidência, utilizando um sistema de detecção composto por um detector proporcional de geometria $4 \pi$ e um cintilador de $\mathrm{NaI}(\mathrm{Tl})$ e determinar a probabilidade de emissão gama por decaimento dos gamas mais intensos, utilizando-se um espectrômetro de germânio hiper puro previamente calibrado com fontes padronizadas em sistema primário de ${ }^{152} \mathrm{Eu},{ }^{241} \mathrm{Am},{ }^{60} \mathrm{Co},{ }^{133} \mathrm{Ba} \mathrm{e}{ }^{166 \mathrm{~m}} \mathrm{Ho}$.

O ${ }^{182}$ Ta decai com uma meia-vida de $114,43(0,03)$ dias por emissão de partículas $\beta^{-}$populando os níveis excitados do ${ }^{182} \mathrm{~W}$, o que acarreta a emissão de radiações gamas e/ou emissão de elétrons de conversão interna, no intervalo de energia de $31 \mathrm{keV}$ a $1453 \mathrm{keV}$.

Estas características tornam este radionuclídeo de grande interesse para utilização como padrão secundário uma vez que as energias gamas emitidas encontram-se em um intervalo de energia em que há faltas de padrões $(84 \mathrm{keV}$ a 264 $\mathrm{keV})$.

No primeiro capítulo desta dissertação são abordados os fundamentos teóricos. No capítulo 2 é apresentada a parte experimental relacionada à determinação da taxa de desintegração do ${ }^{182}$ Ta. No capítulo 3 é apresentada a parte experimental relacionada com a determinação das probabilidades de emissão gama por decaimento. No capítulo 4 são apresentados os resultados e discussões e por fim no capítulo 5 são apresentadas as conclusões e sugestões para trabalhos futuros. 


\section{FUNDAMENTOS TEÓRICOS}

\subsection{Instabilidade nuclear}

A instabilidade nuclear pode ser explicada pelo desequilíbrio do número de nucleons que constitui um dado núcleo. Para alcançar a estabilidade, ou seja, atingir o seu estado fundamental, núcleos instáveis emitem radiações eletromagnéticas e/ou corpusculares convertendo um nucleon em outro e por conseqüência, transformando o elemento nuclear numa outra espécie em um estado estável ou instável de energia que para obter a estabilidade emite novas radiações ${ }^{[3,4]}$.

Núcleos instáveis são fontes radioativas e portanto possuem uma grandeza física denominada atividade, um fenômeno que pode ser observado em elementos naturais e artificiais, tal fenômeno é de natureza estocástica.

\subsubsection{Atividade}

A atividade de uma fonte radioativa é definida como o número de desintegrações por unidade de tempo.

$$
A=-\frac{d N}{d t}=N \lambda
$$

Onde:

A é a atividade.

$\mathrm{N}$ o número de núcleos radioativos.

$\lambda$ é a constante de decaimento específico de cada radionuclídeo. 
A unidade de medida de atividade no Sistema Internacional é o becquerel (Bq) e seus múltiplos e submúltiplos, sendo que $1 \mathrm{~Bq}$ equivale a uma desintegração por segundo.

A seguir são apresentadas e discutidas as radiações emitidas no processo de desintegração do ${ }^{182} \mathrm{Ta}$.

\subsubsection{Decaimento beta $\left(\beta^{-}\right)$}

Trata-se de decaimento beta a emissão ou absorção nuclear de partículas providas de carga cuja intensidade é igual a uma carga elementar e de massa de repouso igual a dos elétrons orbitais. Tal decaimento é característico de núcleos leves, sendo este

decaimento o mais comum entre os elementos que buscam a estabilidade ${ }^{[3,4]}$. Para um dado radionuclídeo cuja instabilidade é dada pelo o excesso de nêutrons, o decaimento segue a seguinte equação:

$$
{ }_{\mathrm{Z}}^{\mathrm{A}} \mathrm{X} \rightarrow{ }_{\mathrm{Z}+1}^{\mathrm{A}} Y+{ }_{-1}^{0} \beta+{ }_{0}^{0} \overline{\boldsymbol{v}}_{[4]}
$$

Onde $\mathrm{X}$ e $\mathrm{Y}$ são as espécies nucleares inicial e final, respectivamente e $\bar{v}$ o antineutrino.

Neste tipo de decaimento um nêutron se converte em um próton emitindo uma partícula negativamente carregada e uma outra desprovida de carga e massa, sendo tais partículas a partícula beta e o antineutrino, respectivamente, mantendo desta forma a conservação de energia, do momento linear e do momento angular.

A emissão das partículas beta forma um espectro de energia contínua que vai desde uma energia inicial (igual a zero no caso do decaimento do $\beta^{-}$) até uma energia máxima $\mathrm{E}_{\max }$, que é característica do radionuclídeo emissor. Poucas são as partículas beta emitidas com energia máxima que se deve à existência do antineutrino neste 
decaimento, sendo que a maioria possui uma energia média $\bar{E}$ que é aproximadamente igual a um terço da energia máxima.

\subsubsection{Decaimento gama}

Comumente, o decaimento gama ocorre após um decaimento corpuscular em um núcleo instável, isto ocorre quando a regra de seleção impede o decaimento direto para o estado fundamental, sendo esta a forma no qual o núcleo emana a energia excedente $^{[5]}$. No decaimento gama, ocorre a emissão de radiações eletromagnéticas ou a transferência da energia excedente do núcleo a um elétron orbital, que da mesma forma pode ou não atingir o estado fundamental, acarretando novos decaimentos gama. Ambas as radiações fornecem um espectro discreto de energia.

No caso da emissão de radiações eletromagnéticas o núcleo emite fótons cuja energia hv corresponde praticamente a diferença entre os níveis energéticos inicial $\mathrm{E}_{i} \mathrm{e}$ final $\mathrm{E}_{f}$, como indica a equação:

$$
h v=\left(E_{i}-E_{f}\right)-\frac{E_{\gamma}^{2}}{2 M c^{2}}
$$

Onde o último fator a direita da equação corresponde à energia de recuo do núcleo emissor. Sendo $E_{\gamma}$ a energia da radiação gama, $M$ a massa do núcleo emissor e $c$ a velocidade da luz.

O processo de emissão de elétron de conversão interna compete com a emissão de raios gama oferecendo uma alternativa ao decaimento gama quando a emissão de fótons é estritamente proibida pela impossibilidade de se originar um fóton sem nenhuma unidade de momento angular em uma dada transição ${ }^{[3]}$. Neste caso, o elétron é ejetado do átomo com uma energia $\mathrm{K}_{\mathrm{e}}$ dada por:

$$
K_{e}=E_{\gamma}-W_{i}[3]
$$


Onde $\mathrm{W}_{\mathrm{i}}$ é a energia de ligação do elétron na órbita $\mathrm{i}$.

Como este processo compete com a emissão de raios gama, a probabilidade de que ocorra a emissão de elétrons é descrita pelo coeficiente de conversão interna $\alpha^{[5]}$, que é definido por:

$$
\alpha=\frac{\lambda_{e c}}{\lambda_{\gamma}}
$$

Onde $\lambda_{\mathrm{ec}} \mathrm{e} \lambda_{\gamma}$ são, respectivamente, as probabilidades de emissão de elétron e de raio gama.

Como os elétrons emitidos podem ser de qualquer órbita eletrônica, o coeficiente de conversão interna total $\alpha_{\mathrm{T}}$ é a representação da contribuição total das diferentes probabilidades de cada órbita ${ }^{[5]}$, ou seja:

$$
\alpha_{T}=\alpha_{K}+\alpha_{L}+\alpha_{M}+\ldots=\frac{\lambda_{e c}}{\lambda_{\gamma}}[5]
$$

O coeficiente de conversão interna é diretamente proporcional ao número atômico, à multipolaridade e inversamente proporcional a energia da transição.

\subsubsection{Rearranjo eletrônico}

Quando ocorre a emissão de um elétron de conversão interna ou qualquer outro processo que retire um elétron da nuvem eletrônica do átomo, este é levado a um estado excitado, pois há uma vacância em uma de suas órbitas. A tendência natural é ocorrer um rearranjo dos elétrons para preencher esta vacância, onde elétrons mais afastados do núcleo e portanto, mais energéticos ocupam essas vacâncias e este preenchimento ocasiona na emissão de raios X ou elétrons Auger cuja energia é dada pela diferença dos estados (níveis) final e inicial ${ }^{[6]}$. No caso de átomos de alto número 
atômico, é maior a probabilidade de emissão de ondas eletromagnéticas cujo comprimento de onda situa-se no espectro dos raios $\mathrm{X}$ (raios $\mathrm{X}$ característicos) já para átomos de baixo número atômico, é maior a probabilidade de ocorrer a emissão de elétrons monoenergéticos (elétrons Auger).

Ambas as radiações fornecem um espectro discreto de energia.

\subsubsection{Interação das partículas beta com a matéria}

A interação da radiação beta com a matéria se dá por colisões coulombianas com os elétrons dos átomos que constituem o material absorvedor, gerando íons no meio no qual se propaga. As partículas betas descrevem um caminho tortuoso no meio de propagação, uma vez que, as massas das partículas envolvidas na interação são iguais. Algumas vezes, a interação pode ocorrer com o campo coulombiano do núcleo ${ }^{[6]}$.

De acordo com a teoria clássica do eletromagnetismo, partículas carregadas quando aceleradas emitem radiação, fenômeno este denominado bremmstrahlung, portanto a transferência linear de energia de uma partícula beta é dada por:

$$
\left(\frac{d E}{d x}\right)_{\text {total }}=\left(\frac{d E}{d x}\right)_{\text {coul }}+\left(\frac{d E}{d x}\right)_{\text {brems }}[6]
$$

O último termo, correspondente à radiação de bremmstrahlung que só se torna significativo para partículas betas de altas energias em absorvedores de alto número atômico.

\subsubsection{Interação das radiações gama com a matéria}

As radiações gama são radiações desprovidas de carga e em virtude desta característica, estas radiações não interagem coulombianamente com o meio absorvedor. Sua interação se dá por meio de colisões elásticas, inelásticas ou absorção 
completa com os elétrons e em algumas vezes com o núcleo atômico. Em uma única interação a radiação gama terá suas propriedades iniciais modificadas, ou seja, interação catastrófica ${ }^{[6]}$. A interação da radiação gama com o meio absorvedor se dá por vários processos, o que depende do número atômico do absorvedor e da energia do fóton na interação. Os três processos mais significativos são:

- O efeito fotoelétrico.

* O espalhamento Compton.

A produção de pares.

A distribuição relativa destes três processos para diferentes materiais absorvedores com energias de raios gama são ilustrados na FIG 1.1, onde a linha da esquerda representa a energia para o qual a absorção fotoelétrica e espalhamento Compton são probabilisticamente prováveis em função do número atômico absorvedor. A linha à direita representa a energia para o qual o espalhamento Compton e produção de pares são probabilisticamente prováveis.

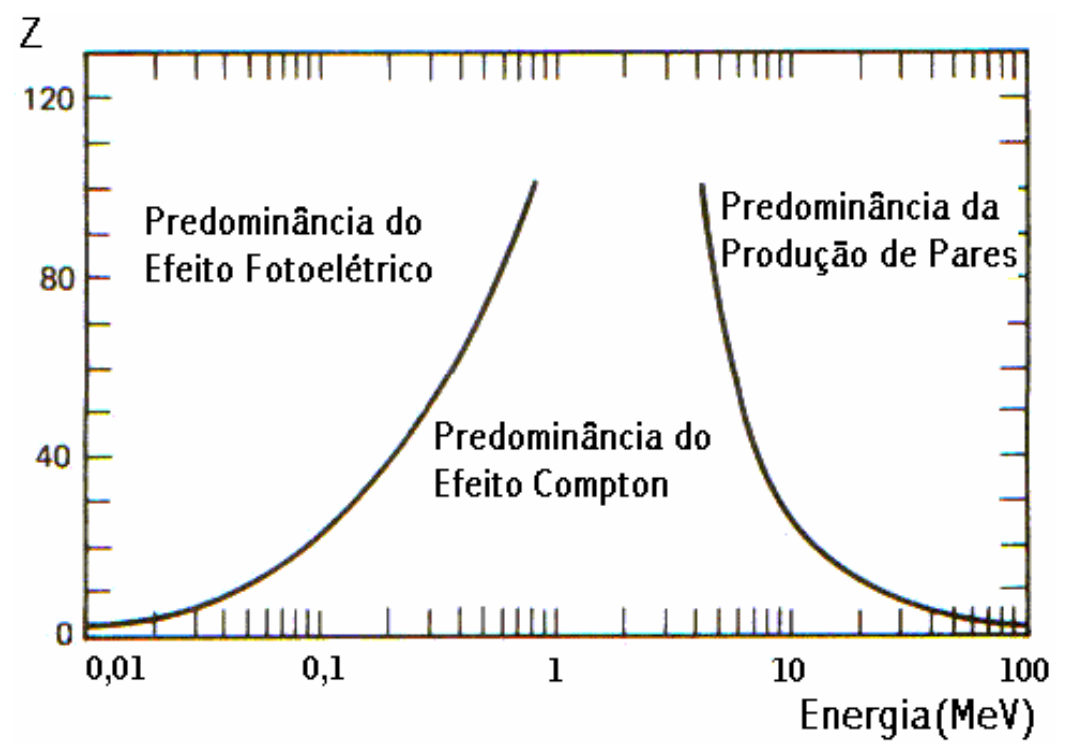

FIGURA 1.1 Os três processos de interação e suas regiões predominantes ${ }^{[6]}$. 
Observa-se neste gráfico (FIG.1.1) a predominância de três áreas. Na região de baixa energia ocorrem principalmente interações pelo processo fotoelétrico que é diretamente proporcional a $Z^{5}$ e inversamente proporcional a $E_{\gamma}{ }^{7 / 5}$. Na região de energias intermediárias ocorrem principalmente interações pelo espalhamento Compton, sendo a probabilidade de ocorrer este espalhamento proporcional a $\mathrm{Z}$ e inversamente proporcional a $\mathrm{E}_{\gamma}$. Na região de altas energias é predominante o processo de produção de pares com probabilidade de ocorrer diretamente e proporcional a $\mathrm{Z}^{2} \mathrm{e}$ proporcional a $\mathrm{E}_{\gamma}$, esse fenômeno ocorre a partir de $1022 \mathrm{keV}$.

\subsection{Medida absoluta da atividade}

Métodos que se baseiam somente nas taxas de contagens medidas da fonte em estudo, são denominados métodos primários ou medidas absolutas. Tais medidas necessitam apenas do tempo como referência. $\mathrm{O}$ método utilizado neste trabalho foi o método da coincidência, método este que não necessita do conhecimento de parâmetros da eficiência de detecção ou de parâmetros do esquema de decaimento.

O método da coincidência é um método primário que é aplicado na padronização de fontes radioativas que desintegram-se pela emissão de duas radiações distintas como por exemplo $\alpha-\gamma$ e $\beta-\gamma$, emitidas em intervalos de tempo tão pequenos que podem ser considerados simultâneos ${ }^{[7]}$. As radiações são detectadas em dois detectores, cada um com sensibilidade para uma das radiações e em seguida são computados em um sistema todos os eventos coincidentes.

Em uma situação ideal, utilizando uma fonte radioativa de dimensões desprezíveis e esquema de desintegração simples, cuja atividade é $N_{0}$ e as eficiências dos detectores $\varepsilon_{\beta}$ e $\varepsilon_{\gamma}$, para as radiações beta e gama, respectivamente, as taxas de contagens em cada um dos detectores podem ser dadas por:

$$
N_{\beta}=N_{0} \varepsilon_{\beta}
$$




$$
N_{\gamma}=N_{0} \varepsilon_{\gamma}
$$

E para os eventos coincidentes:

$$
N_{c}=N_{0} \varepsilon_{\beta} \varepsilon_{\gamma}
$$

Onde $N_{\beta}$ são as contagens beta, $N_{\gamma}$ são as contagens gama e $N_{c}$ são as contagens em coincidência.

Portanto, multiplicando-se as equações 1.8 e 1.9 e dividindo-as pela equação 1.10, tem-se:

$$
\frac{N_{\beta} N_{\gamma}}{N_{c}}=N_{0}
$$

Deste modo para determinar a atividade da fonte não é preciso conhecer as eficiências dos detectores e $N_{0}$ pode ser obtido diretamente quando se tem, por exemplo, um esquema de decaimento $\beta-\gamma$ e detectores sensíveis para um único tipo de radiação. Já consideradas as correções para tempo morto e radiação de fundo, pode-se obter a atividade da fonte sem a necessidade de conhecer os parâmetros do esquema de decaimento da fonte a ser calibrada.

De acordo com as medidas, também pode ser encontrado o parâmetro de eficiência do detector beta, com $\varepsilon_{\beta}$ equivalente a $N_{c} / N_{\gamma}$, e o parâmetro de eficiência do detector gama, com $\varepsilon_{\gamma}$ equivalente a $N_{c} / N_{\beta}$. 


\subsubsection{Técnica da extrapolação linear da eficiência}

As considerações apresentadas no item 1.7 correspondem a uma situação ideal, o que limita este método, pois em situações reais os radionuclídeos apresentam em sua maioria, um esquema de desintegração complexo, envolvendo algumas vezes mais de dois tipos de radiações e desta forma contribuindo na taxa de contagem, tendo em vista que os detectores apresentam uma probabilidade de detecção a outros tipos de radiações.

Quando se passa ao caso real é fundamental que sejam conservadas as características do método de coincidência no caso ideal, evitando a introdução ou minimizando os efeitos das eficiências dos detectores e dos parâmetros nucleares, e desta forma, conservando a principal característica do método.

Para um caso prático, em que o radionuclídeo decai por $\beta-\gamma$ e apresenta um esquema de desintegração complexo, por exemplo, com a emissão de elétrons pelo processo de conversão interna, a equação para as contagens beta considerando outros eventos, passa ser escrita de maneira simplificada como:

$$
N_{\beta}=N_{0}\left[\varepsilon_{\beta}+\left(1-\varepsilon_{\beta}\right)\left(\frac{\alpha_{T} \varepsilon_{e c}+\varepsilon_{\beta \gamma}}{1+\alpha_{T}}\right)\right]
$$

A equação 1.9 correspondente às contagens gama, com as devidas correções fica:

$$
N_{\gamma}=N_{0} \frac{\varepsilon_{\gamma}}{1+\alpha_{T}}
$$


Para as contagens de coincidência a equação 1.10 corrigida assume a forma de:

$$
N_{c}=N_{0}\left[\varepsilon_{\beta} \frac{\varepsilon_{\gamma}}{1+\alpha_{T}}+\left(1-\varepsilon_{\beta}\right) \varepsilon_{c}\right]
$$

Onde:

$\varepsilon_{\beta} \quad$ é a eficiência beta,

$\varepsilon_{\beta \gamma}$ é a eficiência do detector beta para as radiações gama,

$\alpha_{T} \quad$ é o coeficiente de conversão interna total,

$\varepsilon_{e c} \quad$ é a eficiência do detector beta para elétrons de conversão,

$\varepsilon_{\gamma} \quad$ é a eficiência gama,

$\varepsilon_{c} \quad$ é a eficiência de coincidência gama-gama.

Quando a medida na via gama é feita selecionando-se apenas o pico de absorção total a equação 1.14 é dada por:

$$
N_{c}=N_{0} \varepsilon_{\beta} \frac{\varepsilon_{\gamma}}{1+\alpha_{T}}
$$

Do mesmo modo que é determinada a equação 1.11 , encontra-se uma equação para determinar $N_{0}$ multiplicando as equações $1.12 \mathrm{com} 1.13$ e dividindo por 1.15 obtém-se: 


$$
\frac{N_{\beta} N_{\gamma}}{N_{c}}=N_{0}\left[1+\frac{1-\varepsilon_{\beta}}{\varepsilon_{\beta}}\left(\frac{\alpha_{T} \varepsilon_{e c}+\varepsilon_{\beta \gamma}}{1+\alpha_{T}}\right)\right]
$$

Analisando a equação 1.16 , conclui-se que para a determinação de $N_{0}$ se faz necessário o conhecimento dos parâmetros do esquema de desintegração e as probabilidades de detecção. Para solucionar este problema e manter a principal característica do método que consiste na sua independência do conhecimento da eficiência de deteç̧ão e dos parâmetros do esquema de desintegração, aplica-se a Técnica de Extrapolação Linear da Eficiência. ${ }^{[8,9]}$. Segundo esta técnica, a determinação de $N_{0}$ só será possível se houver uma relação funcional entre $N_{\beta}$ e o parâmetro de eficiência $N_{d} N_{\gamma}$, tal que $N_{\beta} \rightarrow N_{0}$, quando $N_{d} N_{\gamma} \rightarrow 1$, tal condição pode ser obtida quando houver um inter-relação biunívoca entre a eficiência de um dado ramo beta, $\varepsilon_{\mathrm{br}}$, por meio de uma função $f_{r}\left(\varepsilon_{\mathrm{bs}}\right)$ que relacione as eficiências dos diversos ramos beta do decaimento do radionuclídeo ${ }^{[10]}$. Portanto a eficiência dos diferentes ramos beta $\varepsilon_{\beta r}$ passa a ser interpretada como uma função de uma eficiência unitária $\varepsilon_{\beta s}$.

$$
\varepsilon_{\beta r}=f_{r}\left(\varepsilon_{\beta s}\right)
$$

Em que, $f_{r} \rightarrow 1$ quando $\varepsilon_{\beta s} \rightarrow 1$.

Na prática o parâmetro $\varepsilon_{\beta s}$ é extrapolado a 1 a partir de uma discriminação gradual em energia das partículas betas emitidas pelo radionuclídeo. Com isso pode-se escrever a equação de coincidência generalizada ${ }^{[8,9]}$, dada por:

$$
N_{\beta}=N_{0} F\left(\frac{N_{C}}{N_{\gamma}}\right)
$$


Segundo Campion ${ }^{[8]}$ a equação de coincidência generalizada pode ser escrita de forma mais conveniente para a sua solução gráfica, relacionando $N_{\beta} N_{\gamma} / N_{c}$ e o parâmetro de ineficiência $\left[1-\left(N_{d} / N_{\gamma}\right)\right] /\left(N_{d} N_{\gamma}\right)$ por meio de uma relação funcional G, cuja a variação é mais lenta que a da equação 1.18.

Deste modo, quando o parâmetro de ineficiência $\left[1-\left(N_{d} / N_{\gamma}\right)\right] /\left(N_{d} N_{\gamma}\right)$ tender a zero, a função $G$ tenderá a 1 e $N_{\beta} N_{\gamma} / N_{c}$ tenderá a $N_{0}$.

Logo a equação de coincidência é dada por:

$$
\frac{N_{\beta} N_{\gamma}}{N_{c}}=N_{0} G\left(\frac{1-N_{C} / N_{\gamma}}{N_{C} / N_{\gamma}}\right)
$$

Usando-se a razão $N_{\beta} N_{\gamma} / N_{c}$ como a variável dependente e o parâmetro de ineficiência $\left[1-\left(N_{d} N_{\gamma}\right)\right] /\left(N_{d} N_{\gamma}\right)$ como a variável independente, pode-se obter a taxa de desintegração $N_{0}$ a partir do gráfico $N_{\beta} N_{\gamma} / N_{c}$ versus $\left[1-\left(N_{C} / N_{\gamma}\right)\right] /\left(N_{C} / N_{\gamma}\right)$ de modo que $N_{\beta} N_{\gamma} / N_{c}$ é dependente da função $G$.

O valor extrapolado obtido por ajuste polinomial dos dados experimentais, fornece a taxa de desintegração $N_{0}$.

A variação do parâmetro de eficiência pode ser obtida pelo uso de absorvedores externos, por auto-absorção na fonte, por discriminação eletrônica, ou qualquer outro método que possibilite a variação da eficiência beta, desde que as probabilidades de detecção $\varepsilon_{\beta \gamma}, \varepsilon_{\mathrm{ec}}$ e $\varepsilon_{\gamma}$ sejam constantes ou nulas no intervalo de variação da eficiência beta $^{[10]}$.

Pela técnica da extrapolação linear da eficiência é ajustada uma reta onde o coeficiente angular corresponde ao produto da atividade da fonte pela constante de correção, devido ao esquema de desintegração e ao sistema de detecção utilizado, e o coeficiente linear à taxa de desintegração procurada.

A medida de coincidência é feita selecionando-se o fotopico de absorção total de uma energia gama em coincidência com a radiação beta. A escolha recai nos gamas 
mais intensos e que apresentem menor coeficiente de conversão interna, o que resultará numa reta com menor coeficiente angular e um coeficiente linear com menor incerteza.

\subsection{Espectroscopia gama}

A espectroscopia gama é uma técnica analítica que estuda núcleos instáveis que decaem para configurações mais estáveis emitindo radiações eletromagnéticas. Muitas vezes, esta técnica é aplicada na identificação de materias, na determinação das probabilidades de emissão gama dos diversos níveis populados, no conhecimento das energias das transições e na compreensão da estrutura nuclear. Para tanto, características do sistema de detecção devem ser bem estabelecidas, como por exemplo, resolução em energia do detector que permite identificação da energia gama emitida e sua eficiência de detecção para uma dada energia, informação esta que é fornecida por meio de uma curva de calibração em eficiência.

O pico de absorção total de uma dada transição corresponde à total absorção e conversão da energia do fóton incidente em cargas elétricas cujo número de eventos segue uma distribuição gaussiana e sua centróide fornece o valor da energia deste fóton. $\mathrm{Na}$ formação de um dado fotopico pode-se conhecer a resolução do detector, sendo tal característica diretamente proporcional à raiz quadrada do números de cargas coletadas, a largura a meia altura fornece a resolução do detector na região da energia de interesse $\mathrm{e}^{[11,12]}$.

A curva de calibração em eficiência de um espectrômetro gama para uma determinada geometria de contagem é obtida a partir da medida de fontes radioativas padrões com atividades, energias e intensidades gama muito bem conhecidas e meiasvidas suficientemente longas para não influir na taxa de contagem obtida. A curva de calibração em eficiência consiste em uma função polinomial que relaciona com exatidão a eficiência de detecção de um dado sistema para uma certa energia gama. Comumente, tal função é descrita por um polinômio logarítmico. 
A eficiência absoluta de detecção é definida como a razão entre o número de fótons detectados e o número de fótons emitidos, conforme indica a equação 1.20 , apresentando uma característica probabilística.

$$
\varepsilon=\frac{N_{\text {fótons }} \text { det }}{N_{\text {fótons }} \text { emit }}
$$

No caso da medida do fotopico de absorção total esta eficiência é denominada eficiência de pico e pode ser obtida como a razão entre a área do fotopico de absorção total e o número de fótons emitidos ${ }^{[6]}$ :

$$
\varepsilon_{\gamma}\left(E_{\gamma}\right)=\frac{S\left(E_{\gamma^{\prime}}\right)}{A \times I\left(E_{\gamma}\right) \times \Delta t}
$$

Onde:

$\varepsilon\left(E_{\gamma i}\right)$ é eficiência de pico para o i-ésimo gama de energia $\mathrm{E}$;

$S\left(E_{\gamma}\right)$ é a área sob o fotopico de absorção total do i-ésimo gama de energia $E$;

A é a atividade da fonte radioativa no momento da medida;

$I\left(E_{\gamma}\right)$ é a probabilidade de emissão por decaimento do i-ésimo gama de energia $E$

$\Delta t \quad$ é o intervalo de tempo de medida.

Para a determinação da eficiência, alguns fatores de correção que influenciam os resultados devem ser introduzidos na equação 1.21. Tais como:

$f_{\tau} \quad$ fator de correção para tempo morto;

$f_{A}$ fator de atenuação e auto-absorção no envoltório da fonte;

$f_{G} \quad$ fator de correção para a geometria da medida;

$f_{c} \quad$ fator de correção para o efeito soma. 
Para determinação da probabilidade de emissão gama por decaimento a mesma equação 1.21 é utilizada, sendo que $I_{\gamma}\left(E_{\gamma i}\right)$ é agora a incógnita e $\varepsilon$ obtida da curva de calibração. Logo:

$$
I\left(E_{\dot{\mu}}\right)=\frac{S\left(E_{\gamma^{\prime}}\right)}{A \times \Delta t \times \varepsilon_{\gamma}\left(E_{\dot{\gamma}}\right) \times f_{\tau} \times f_{A} \times f_{G} \times f_{C}}
$$




\section{PadronizaÇÃo do ${ }^{182}$ Ta.}

A padronização do ${ }^{182} \mathrm{Ta}$ foi realizada no sistema de medida absoluta $4 \pi(\mathrm{PC})-$ $\mathrm{NaI}(\mathrm{Tl})$ com a aplicação do método da coincidência recorrendo à técnica da extrapolação linear da eficiência, descrita no capítulo 1 , onde foram selecionados dois intervalos de energia gama para formar os eventos coincidentes com as partículas beta.

\section{$2.1 \quad$ Sistema $4 \pi(\mathrm{PC})-\mathrm{NaI}(\mathrm{Tl})$}

O sistema $4 \pi(\mathrm{PC})-\mathrm{NaI}(\mathrm{Tl})$ é constituído de um contador proporcional de geometria $4 \pi$ para a detecção das radiações corpusculares emitidas pelo ${ }^{182}$ Ta e um cristal cintilador de $\mathrm{NaI}(\mathrm{Tl})$ acoplado ao detector proporcional a fim de detectar as radiações eletromagnéticas emitidas. Ambos os detectores estão associados a um sistema de módulos eletrônicos para análise e coleção das radiações detectadas.

\subsubsection{Contador Proporcional $4 \pi(\mathrm{PC})$}

O detector utilizado neste trabalho é um contador proporcional com geometria $4 \pi$ operando com gás fluente usado para a detecção das partículas beta. Este sistema apresenta uma eficiência de detecção de partículas beta próxima de $98 \%$, para partículas beta de alta energia e eficiência para detecção de radiação gama menor que 0,5\%. O seu tempo de recuperação é da ordem de 100 ns.

O contador proporcional é constituído por duas partes idênticas feitas em um bloco de latão, com conexões para entrada e saída de gás. Cada parte interna possui uma forma aproximadamente cilíndrica medindo $3 \mathrm{~cm}$ de diâmetro e 7,5 $\mathrm{cm}$ de 
comprimento. No interior de cada uma das partes é posicionado um anodo de aço inoxidável com diâmetro de $25 \mu \mathrm{m}$, fixado por isoladores de teflon nas duas extremidades. As duas partes são unidas e vedadas por meio de anéis de borracha. Entre elas há uma lámina de $0,32 \mathrm{~cm}$ de espessura feita também de latão com dois orifícios. O maior, com diâmetro de 4,0 cm utilizado para o posicionamento da fonte radioativa, e o menor com diâmetro de $1,5 \mathrm{~cm}$ utilizado para puxar a lâmina como mostra a FIG.2.1, permitindo que a fonte radioativa seja trocada sem a necessidade de abrir o detector. Este detector opera na região proporcional com uma tensão de $1300 \mathrm{~V}$ para partículas alfa e $2050 \mathrm{~V}$ para a detecção de partículas beta.

O gás utilizado é uma mistura de $90 \%$ de argônio e 10\% metano. O contador opera a uma pressão de 1 atm, aproximadamente. Este modelo de contador proporcional também conhecido como "pill box", permite que a fonte seja posicionada dentro do volume sensível do detector. A vantagem da contagem da fonte interna, é que não há janelas entre o volume sensível do contador e a fonte radioativa, o que minimiza os efeitos de absorção das radiações de baixas energias. Este detector também pode trabalhar em uma configuração de alta pressão desde que esteja acoplado a um sistema de controle da pressão do gás.

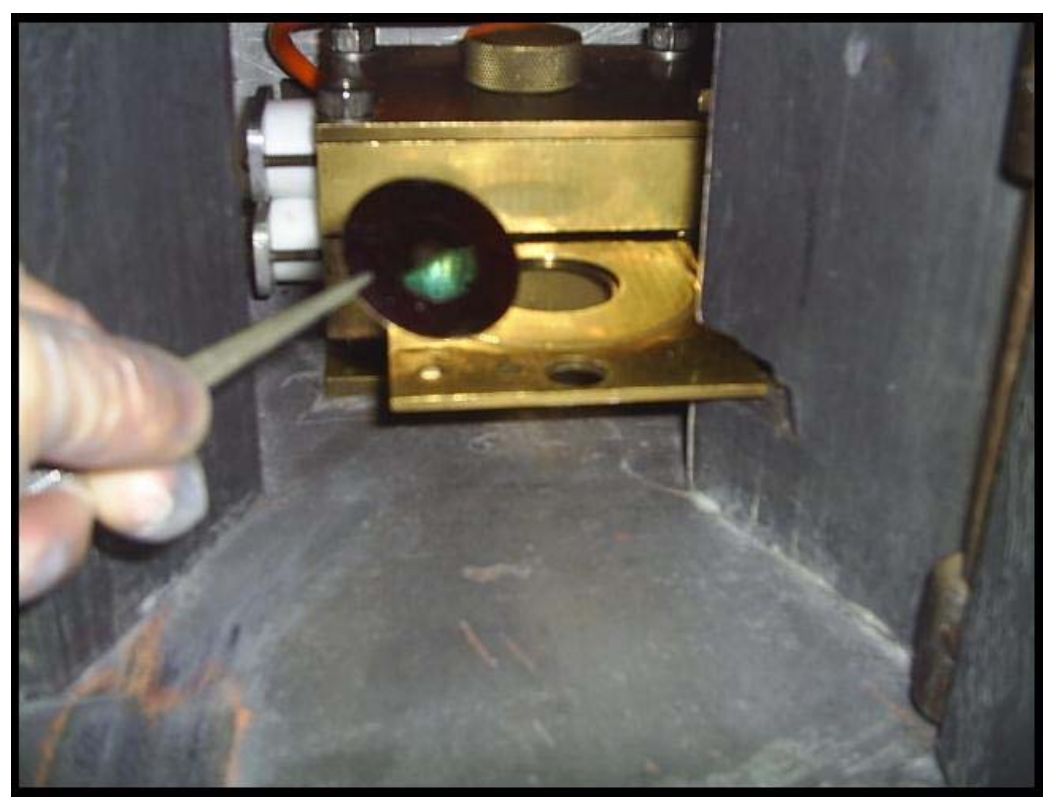

FIGURA 2.1 Detector proporcional utilizado para a detecção das partículas beta. 
O princípio de funcionamento do contador proporcional baseia-se em uma das propriedades das radiações, ionizar o meio no qual se propaga.

Ao se propagar em um gás, a radiação produz pares de íons que são acelerados para seus respectivos eletrodos através de um campo elétrico. No decorrer do percurso rumo ao anodo, o elétron adquire uma energia cinética suficiente para produzir novas ionizações e desta forma gerando uma avalanche e amplificando o pulso dentro do próprio detector. Quando todos os elétrons são coletados a avalanche se extingue gerando um pulso proporcional à energia da radiação incidente ${ }^{[6]}$. $O$ fator de multiplicação do contador proporcional é da ordem de $10^{5}$.

\subsubsection{Iodeto de Sódio NaI(Tl)}

Neste trabalho o detector utilizado para a detecção da radiação gama é um cristal cintilador de $\mathrm{NaI}(\mathrm{Tl})$ plano com diâmetro de $76 \mathrm{~mm}$ por $76 \mathrm{~mm}$ de altura. $\mathrm{O}$ cristal cintilador acoplado à fotomultiplicadora é encapsulado em um tubo de alumínio hermeticamente selado para evitar sua deteriorização devido o cristal ser higroscópico.

O sistema está inserido dentro de uma torre cilíndrica de chumbo, que protege o cristal de iodeto de sódio das radiações de fundo.

O processo de detecção nos cristais inorgânicos, como é o caso do $\mathrm{NaI}(\mathrm{Tl})$, ocorre pela interação dos fótons incidentes com as moléculas do cristal levando-as a uma configuração instável de energia o que acarreta em emissão de fótons no espectro do visível para voltar ao seu estado fundamental. Tais fótons são coletados pela fotomultiplicadora acoplada opticamente ao cristal, convertendo os sinais luminosos em pulsos elétricos. A altura de pulso gerado é proporcional à intensidade luminosa que chega a fotomultiplicadora que por sua vez é proporcional à energia dos fótons incidentes emitidos pela fonte ${ }^{[13]}$. 


\subsubsection{Sistema eletrônico}

O sistema eletrônico associado aos detectores é um sistema convencional para este tipo de medida ${ }^{[14]}$, constituído de pré-amplificadores, amplificadores de pulso, analisadores monocanais, módulos de soma, módulos geradores de atraso e módulos geradores de porta e atraso.

A coleta de dados é feita com o auxílio de um conversor de tempo para amplitude de pulso o módulo TAC (Time to Amplitude Converter), associado a um analisador multicanal (MCA) $)^{[14]}$.

Utilizando o TAC juntamente com os módulos geradores de porta e atrasos e o multicanal, é possível obter um espectro em tempo FIG. 2.2. A análise fornece o registro das contagens beta, gama e dos eventos coincidentes.

Na FIG.2.3 é apresentado o diagrama do sistema eletrônico, neste diagrama destacamos que os pulsos provenientes do contador proporcional $4 \pi$ após serem préamplificados e amplificados, são enviados a um módulo analisador de altura de pulso, o SCA Timing (Single Channel Analyser- Timing), onde são discriminados os pulsos de ruído eletrônico. Os pulsos selecionados são enviados simultaneamente a dois geradores de porta e atraso e posteriormente enviados ao módulo TAC para a coleção de dados.

De modo análogo, os pulsos provenientes do cristal cintilador $\mathrm{NaI}(\mathrm{Tl})$, acoplados á um tubo fotomultiplicador, são pré-amplificados e amplificados e enviados a dois analisadores monocanal onde são selecionados os intervalos de energia gama de interesse. Nesta medida, são utilizados dois analisadores monocanal na via gama, pois são selecionados dois intervalos de energia distintos.

$\mathrm{Na}$ coleta de dados por meio do método TAC desenvolvido no LMN, os geradores de porta e atraso são denominados gerador 1 e 2 onde o módulo gerador de porta e atraso 1 recebe os pulsos das vias beta e gama e os envia para a entrada início do módulo TAC para dar início à contagem do tempo. $\mathrm{O}$ gerador de porta e atraso 2 recebe os pulsos das vias beta e os pulsos atrasados das via gamas e os envia para a 
entrada fim do módulo TAC para dar o término à contagem de tempo. Os sinais iníciofim são por sua vez enviados ao analisador multicanal onde são acumuladas as contagens.

Na FIG.2.2 é apresentado o espectro onde, o pico estreito da esquerda corresponde às contagens beta, o pico estreito do centro corresponde às contagens gama $I$ e o ultimo pico estreito a direita corresponde às contagens do gama II, os dois picos mais alargados no centro correspondem às contagens em coincidências $\left(\mathrm{N}_{\mathrm{c} 1}\right)$ e $\left(\mathrm{N}_{\mathrm{c} 2}\right)$, que contabilizam os eventos coincidentes das contagens beta com os gamas $I$ e gamas II, respectivamente.

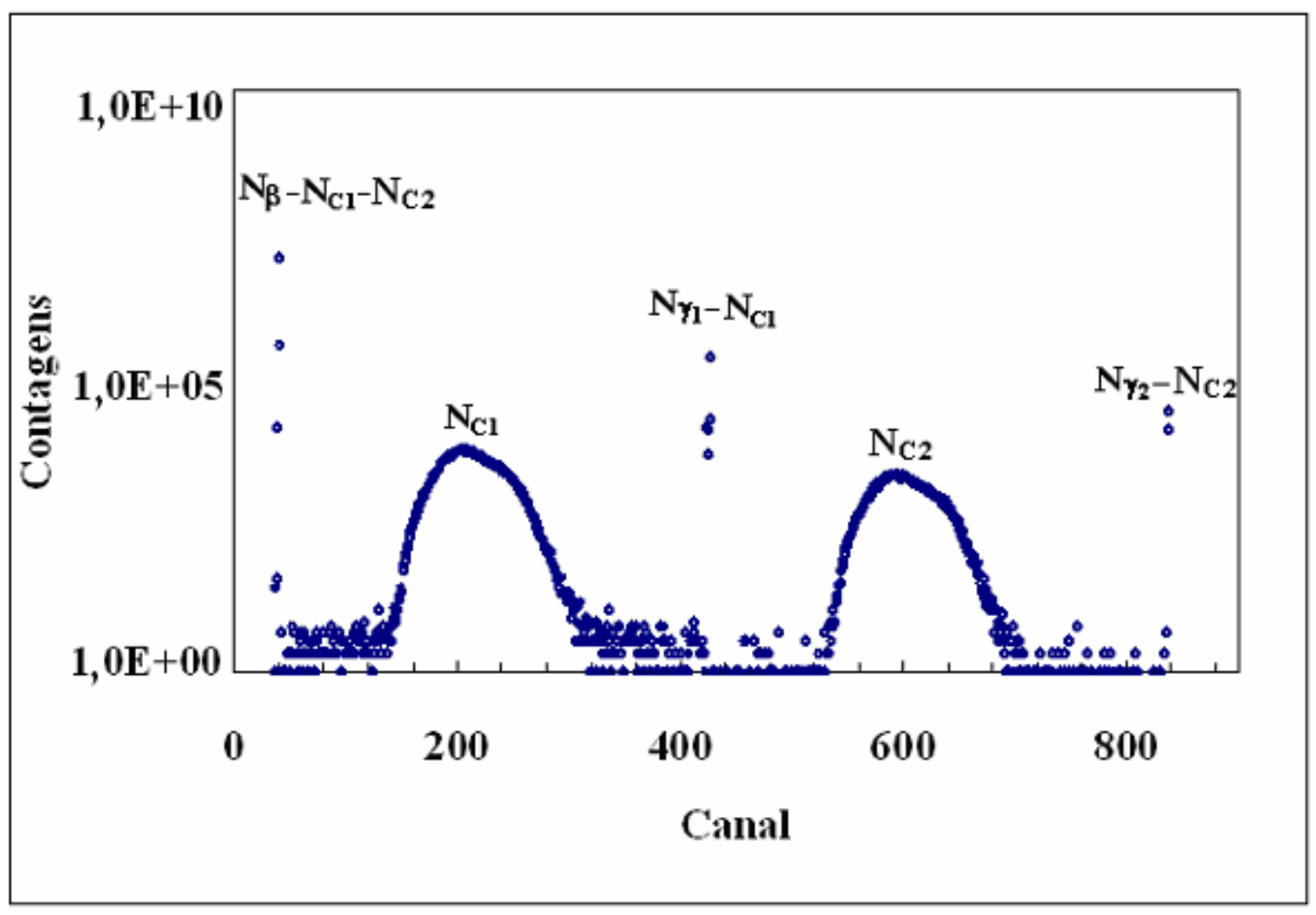

FIGURA 2.2 Espectro de coincidências com a discriminação de dois intervalos de energia gama. 


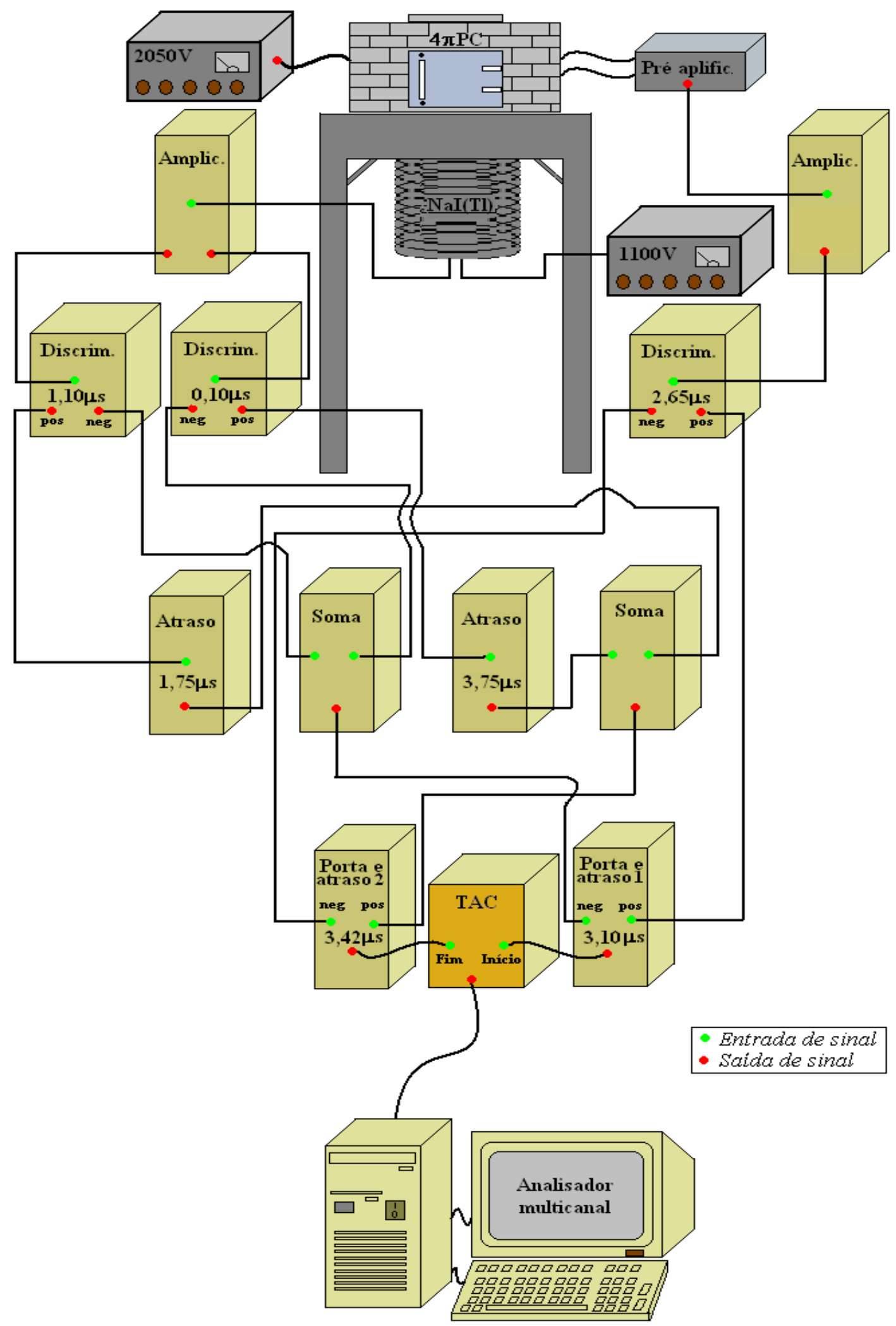

FIGURA 2.3 Sistema eletrônico convencional para dois intervalos de energia $\gamma$. 


\subsection{Cálculo da atividade}

O cálculo da atividade das fontes medidas no sistema de coincidências é feito por meio do programa CONTAC $^{[15]}$ desenvolvido no LMN. Neste programa estão incorporadas as correções aplicadas para determinação da atividade, estas correções estão detalhadas no item 2.2.1.

O programa CONTAC foi desenvolvido em linguagem FORTRAN e utiliza três arquivos de entrada e um arquivo de saída.

Os arquivos de entrada são:

Espectro.chn, arquivo binário fornecido pelo multicanal onde está registrado o espectro da fonte medida.

Bg.chn, arquivo binário fornecido pelo multicanal onde está registrado o espectro da radiação de fundo.

Contac.dat, arquivo texto (ASCII) onde são fornecidas as informações relacionadas à fonte em análise que são:

Meia-vida do radionuclídeo em dias e sua incerteza em porcentagem;

* Data e hora de referência do radionuclídeo;

Intervalo em canal do início e término da área correspondente as contagens beta;

Intervalo em canal do início e término da área correspondente as contagens do gama I;

Intervalo em canal do início e término da área correspondente as contagens coincidências 1 ;

Intervalo em canal do início e término da área correspondente as contagens do gama II;

Intervalo em canal do início e término da área correspondente as contagens coincidências 2;

Intervalo estimado do início e término em canal das coincidências acidentais.

Número de canais; 
Tempo real e tempo vivo da medida de radiação de fundo em segundos;

Tempo real e tempo vivo da medida da fonte em segundos.

O arquivo de saída é denominado Contac.out e fornece diversas informações da medida obtidas por meio da análise do espectro em tempo como o da FIG.2.2. Neste arquivo de saída é possível obter:

Valor da eficiência beta e sua incerteza em porcentagem, para as duas coincidências;

Valor da ineficiência beta e sua incerteza em porcentagem, para as duas coincidências;

Valor da atividade em becquerel e sua incerteza em porcentagem, para as duas coincidências;

Valor da eficiência gama $I$ e gama II e suas respectivas incertezas em porcentagem.

\subsubsection{Correções aplicadas}

Correções são aplicadas nas taxas de contagens observadas em virtude das condições reais em que são realizadas as medidas para a determinação da atividade, são elas: correção para a radiação de fundo (BG), correção para o tempo morto do sistema de detecção $4 \pi(\mathrm{PC})-\mathrm{NaI}(\mathrm{Tl})$, correção para o decaimento da fonte durante as medidas e correção para as coincidências acidentais que podem ocorrer dentro do tempo de resolução. Todas estas correções são feitas por meio do programa CONTAC.

\subsubsection{Correção da radiação de fundo}

A radiação de fundo é a radiação que não é proveniente da fonte a ser medida, e portanto, deve ser subtraída do espectro obtido. Para efetuar esta correção foram 
obtidos espectros da radiação de fundo do laboratório nas mesmas condições em que foram efetuadas as medidas das fontes de ${ }^{182} \mathrm{Ta}$.

\subsubsection{Correção do tempo morto}

No sistema de detecção existe um intervalo mínimo de tempo que separa dois eventos para que sejam registrados como pulsos distintos, denominado tempo morto, que representa o tempo em que o sistema se encontra processando eventos coletados, e portanto, está indisponível para outras aquisições. Em um sistema de detecção, o tempo morto total do sistema corresponde ao tempo morto intrínseco do detector juntamente com o tempo morto do sistema eletrônico associado que geralmente é muito pequeno. Devido ao tempo morto, grandes perdas de contagem poderão ocorrer quando o radionuclídeo a ser mensurado possuir uma alta atividade. Porém, no sistema utilizado, este tempo é dado pelo tempo morto do multicanal, pois seu tempo morto é o maior em relação ao tempo morto de todos os outros componentes do sistema de detecção.

A correção para este efeito é obtida por meio da razão dos tempos, ou seja, a razão entre o tempo vivo (time live) com tempo real de medida (time real).

\subsubsection{Verificação da correção do tempo morto}

Para verificação da validade do uso do tempo morto do multicanal, foi feito um estudo por meio de medidas seqüenciais realizadas com uma fonte de alta atividade. A fonte escolhida tem uma constante de decaimento grande e desta forma, foi possível seguir o decaimento de sua atividade em um menor intervalo de tempo.

A fonte escolhida foi o ${ }^{24} \mathrm{Na}$, seu decaimento ocorre pela emissão de partículas

$\beta^{-}$populando os níveis excitados do ${ }^{24} \mathrm{Mg}$ com a emissão de radiações gama, com um período de meia-vida de $14,9590(12) \mathrm{h}^{[16]}$. 
As medidas foram realizadas no mesmo sistema em que foram medidas as fontes de ${ }^{182}$ Ta e observou-se a validade da correção feita pelo programa Contac por meio do comportamento da curva da FIG.2.4.

Esperava-se que a curva apresentasse uma inclinação nula por todo intervalo de tempo morto estudado, pois o programa fornece a atividade da fonte na data de referência estabelecida, no entanto observou-se que para altas atividades, ou seja, alto tempo morto o comportamento da curva não se manteve constante.

Como as medidas realizadas para as fontes de ${ }^{182} \mathrm{Ta}$ neste mesmo sistema apresentou um tempo morto máximo da ordem de $8 \%$, no qual ser observado na curva da FIG.2.4, mostrou que a correção aplicada pelo programa neste intervalo garante a confiabilidade dos resultados.

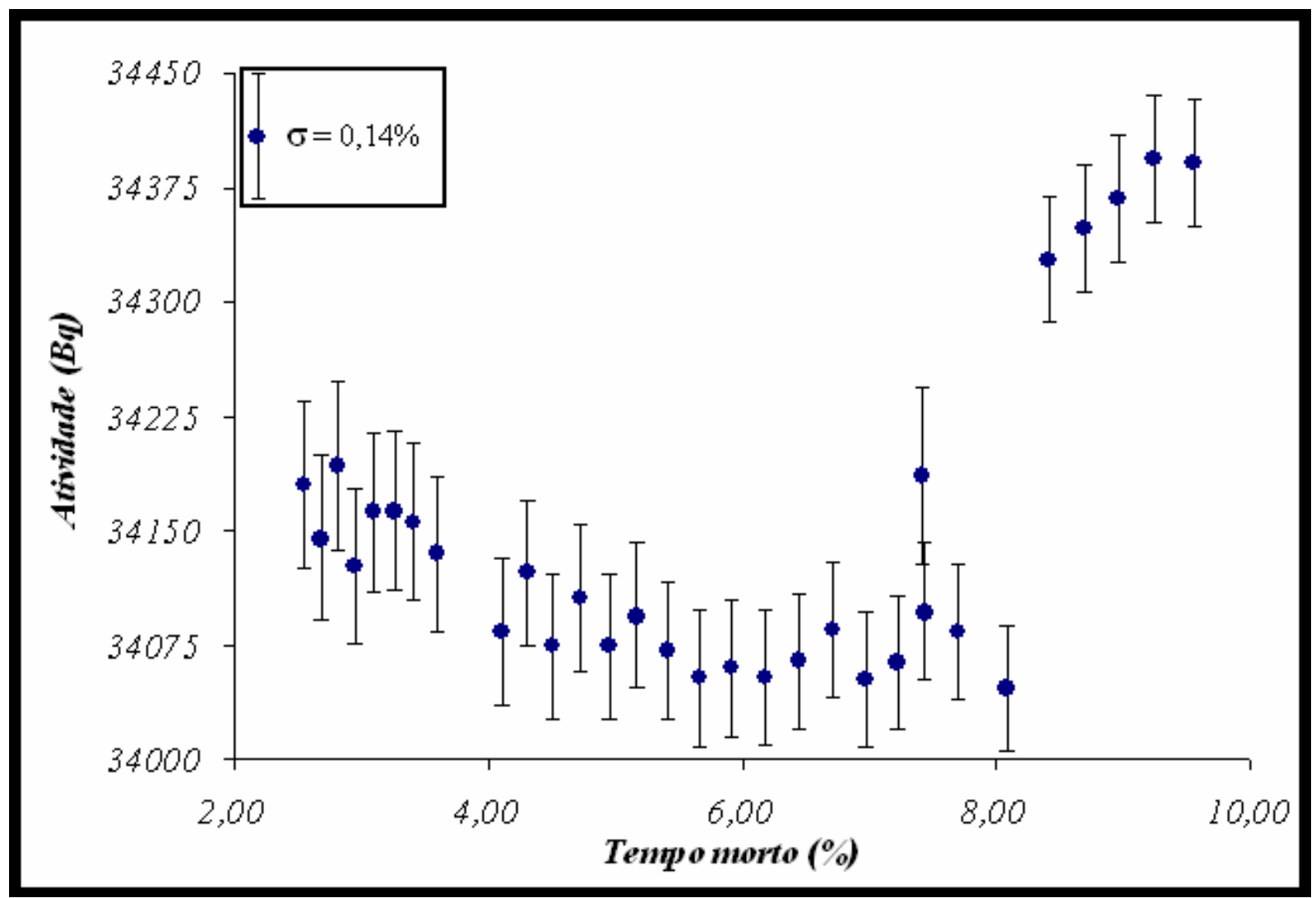

FIGURA 2.4 Curva de comportamento da correção da atividade em função do tempo morto. 


\subsubsection{Correção durante o decaimento da fonte}

Em radionuclídeos cuja constante de decaimento é relativamente alta, o decaimento da fonte durante a medida pode alterar os resultados, por isso esta correção deve ser aplicada. A taxa de contagem é corrigida por meio da equação 2.1.

$$
N_{r}=N \frac{\lambda t}{1-e^{-\lambda t}} e^{\lambda\left(t_{m}-t_{r}\right)}
$$

Onde:

$\mathrm{N}_{\mathrm{r}}$ é a taxa de desintegração na data da referência;

$\mathrm{N}$ é a taxa de desintegração na data da medida;

t é o tempo de medida;

$\mathrm{t}_{\mathrm{m}}$ é a data da medida;

$\mathrm{t}_{\mathrm{r}}$ é a data de referência;

$\lambda$ é a constante de decaimento da fonte em questão.

\subsubsection{Correção das coincidências acidentais}

Como já mencionado, a taxa de coincidências é obtida pela detecção de duas radiações distintas consideradas simultâneas em relação ao tempo de resolução do sistema de deteç̧ão. No entanto, podem ser considerados coincidentes eventos de núcleos distintos, pois o tempo de resolução assume um valor finito. Estes eventos são denominados coincidências espúrias ou coincidências acidentais. As coincidências acidentais podem interferir no número de contagens, acarretando em um erro no valor absoluto da atividade. De acordo com o formalismo de Cox e Isham $^{[17]}$ e adaptado por Smith $^{[18]}$ estes eventos podem ser corrigidos em função do tempo de resolução e do tempo morto quando este for considerado igual para as vias beta e gama. Este cálculo está incorporado no programa CONTAC. 


\subsection{Preparação das amostras medidas no sistema $4 \pi(\mathrm{PC})-\mathrm{NaI}(\mathrm{Tl})$}

As fontes radioativas medidas no sistema de detecção $4 \pi(\mathrm{PC})-\mathrm{NaI}(\mathrm{Tl})$ foram confeccionadas no laboratório em substratos de Collodion (nitrato de celulose) com espessura de aproximadamente $20 \mu \mathrm{g} . \mathrm{cm}^{-2}$ metalizados com Au sobre os quais é depositado o material radioativo.

\subsubsection{Preparação de substratos de Collodion}

Os substratos de Collodion utilizados na confecção das fontes radioativas são filmes finos obtidos pela deposição de $2 \mathrm{ml}$ de uma solução de Collodion elástico, diluído com acetato de isoamila, numa proporção de 1:1, em uma cuba com capacidade de 20 litros preenchida até a metade com água deionizada, formando na superfície da água uma película elástica com espessura de aproximadamente $20 \mu \mathrm{g} . \mathrm{cm}^{-2}$. Sobre esta superfície são colocadas cuidadosamente arandelas com $4 \mathrm{~cm}$ de diâmetro externo e 2 $\mathrm{cm}$ de diâmetro interno feitas em aço inoxidável de $0,2 \mathrm{~mm}$ de espessura.

Em um curto intervalo de tempo, a película adere ao aço inox e o filme aderido à arandela é recortado cuidadosamente para não rompe-lo. Após a sua remoção as arandelas com o filme são colocadas na posição vertical para secar à temperatura ambiente. Uma vez secas, as arandelas são levadas para metalização com ouro de modo a torná-las condutoras (FIG. 2.5. A).

O mesmo processo é realizado para a confecção dos absorvedores das partículas beta. Neste caso são utilizadas arandelas com diâmetro interno de $4,5 \mathrm{~cm}$ e externo de $5,5 \mathrm{~cm}$ e espessura de 0,2 mm. Estes filmes mais espessos, com $50 \mu \mathrm{g} . \mathrm{cm}^{-2}$, aproximadamente, também são metalizados com ouro e são utilizados para se obter a variação da eficiência do detector beta. Estes filmes colocados sobre e sob a fonte, absorvem gradualmente as partículas de menor energia (FIG. 2.5. B), desta forma, à medida que vão sendo adicionados absorvedores na fonte, menos partículas são 
detectadas, diminuindo a eficiência $\left(N_{c} / N_{\gamma}\right)$ do detector beta e consequentemente, aumentando o parâmetro de ineficiência $\left(1-N_{c} / N_{\gamma}\right) /\left(N_{c} / N_{\gamma}\right)$.

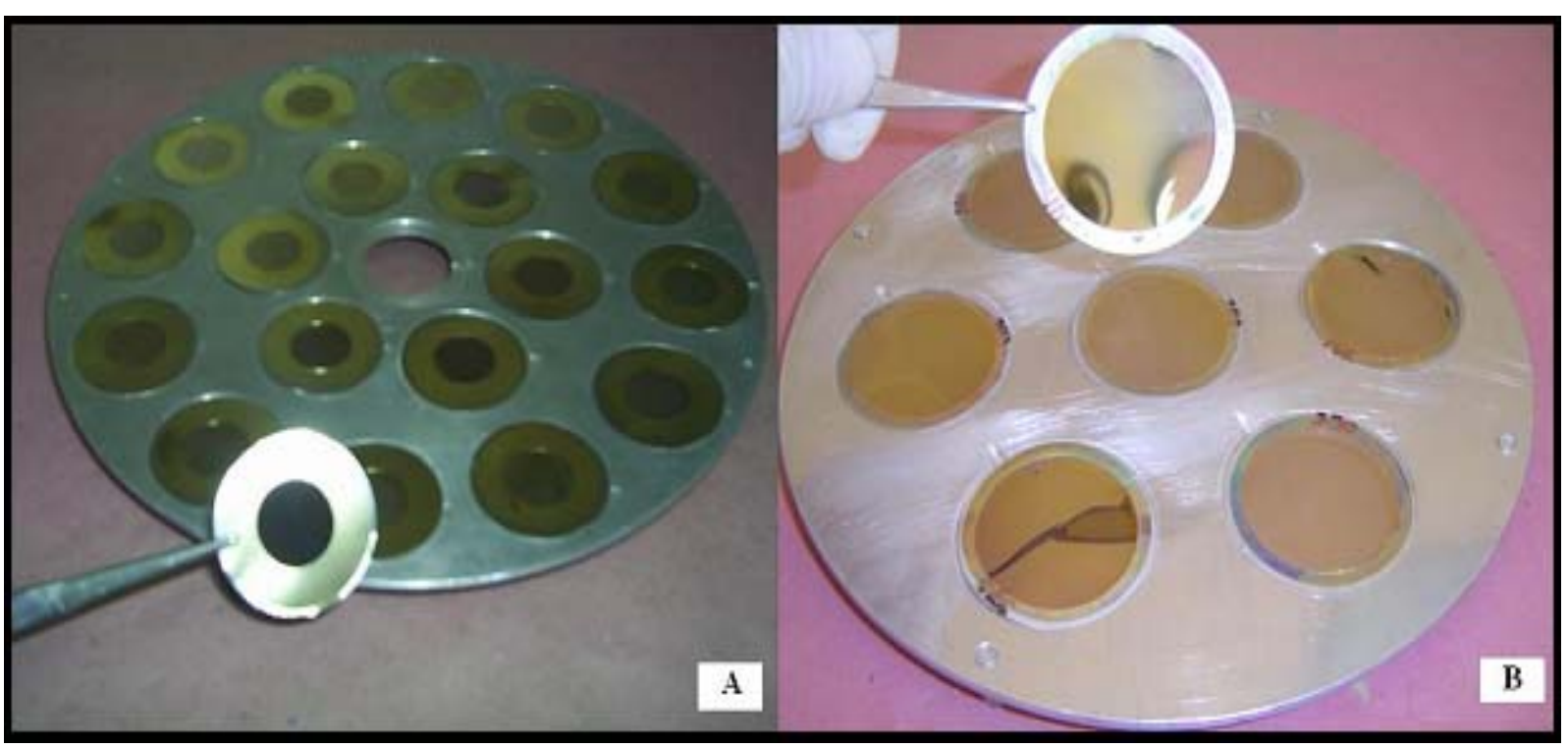

FIGURA 2.5 (A) - Arandelas com Collodion mentalizados para o depósito das fontes. (B) - Arandelas com Collodion metalizados para absorção das partículas $\beta$.

\subsubsection{Produção do ${ }^{182}$ Ta}

As fontes de ${ }^{182} \mathrm{Ta}$ foram produzidas pela irradiação de $1 \mathrm{mg}$ de pó metálico de óxido de tântalo $\left(\mathrm{Ta}_{2} \mathrm{O}_{5}\right)$ depositado em uma cápsula de polietileno, irradiado no reator IEA-R1 do IPEN, pela reação ${ }^{181} \mathrm{Ta}(\mathrm{n}, \gamma){ }^{182} \mathrm{Ta}$, durante 45 minutos em um fluxo de nêutrons térmicos da ordem de $10^{12} \mathrm{~s}^{-1} \cdot \mathrm{cm}^{-2}$.

O tântalo utilizado foi o tântalo natural ${ }^{181} \mathrm{Ta}$ espectroscopicamente puro que apresenta uma porcentagem isotópica de $99,88 \%$, sua secção de choque para nêutrons térmicos é de 20,5 barns $^{[19]}$.

Foi verificada por meio da equação 2.2 a queima do isótopo produzido, fenômeno este que ocorre quando a secção de choque do núcleo produzido $\left({ }^{182} \mathrm{Ta}\right)$ é maior que a secção de choque do núcleo da amostra a ser irradiada $\left({ }^{181} \mathrm{Ta}\right)$, produzindo desta forma um outro isótopo ${ }^{[20]}\left({ }^{183} \mathrm{Ta}\right)$. No caso, a secção de choque do núcleo de 
${ }^{182}$ Ta produzido na reação é de 8000 barns ${ }^{[19]}$, ou seja, quase 400 vezes maior que a do núcleo da amostra primária, produzindo o ${ }^{183} \mathrm{Ta}$ pela reação ${ }^{182} \mathrm{Ta}(\mathrm{n}, \gamma){ }^{183} \mathrm{Ta}$.

$$
N_{C}=N_{A 0} \sigma_{A} \cdot \sigma_{B} \cdot \phi^{2}\left\{\begin{array}{l}
\frac{e^{-\sigma A \phi t}}{\left[\left(\lambda_{B}+\phi \sigma_{B}\right)-\sigma_{A} \phi\right] \cdot\left(\lambda_{C}-\sigma_{A} \phi\right)}+ \\
+\frac{e^{-\left(\lambda_{B}+\phi \sigma_{B}\right)}}{\left[\phi \sigma_{A}-\left(\lambda_{B}+\phi \sigma_{B}\right)\right]\left[\lambda_{B}-\left(\lambda_{B}+\phi \sigma_{B}\right)\right]} \\
+\frac{e^{-\lambda_{C} t}}{\left(\phi \sigma_{A}-\lambda_{C}\right)-\left[\left(\lambda_{B}+\phi \sigma_{B}\right)-\lambda_{C}\right]}
\end{array}\right\}
$$

Onde:

$N_{C} \quad$ número de núcleos terciário, ${ }^{183} \mathrm{Ta}\left(\right.$ núcleos $\left./ \mathrm{cm}^{3}\right)$;

$N_{A 0} \quad$ número de núcleos da amostra primária, ${ }^{181} \mathrm{Ta}\left(\right.$ núcleos $\left./ \mathrm{cm}^{3}\right)$;

$\sigma_{A} \quad$ secção de choque da amostra primária $\left(\mathrm{cm}^{2}\right)$;

$\sigma_{B} \quad$ secção de choque dos núcleos secundários, ${ }^{182} \mathrm{Ta}\left(\mathrm{cm}^{2}\right)$;

$\phi \quad$ fluxo de nêutrons térmicos (nêutrons $/ \mathrm{s} . \mathrm{cm}^{2}$ );

$\lambda_{B} \quad$ constante de decaimento dos núcleos secundários $\left(\mathrm{s}^{-1}\right)$;

$\lambda_{C} \quad$ constante de decaimento dos núcleos terciários, ${ }^{183} \mathrm{Ta}\left(\mathrm{s}^{-1}\right)$;

$t$ tempo de irradiação (s).

Pelo cálculo notou-se que o número de núcleos de ${ }^{183}$ Ta produzido na reação era muito baixo, da ordem de $10^{4}$ núcleos $/ \mathrm{cm}^{3}$, comparado ao número de núcleos produzidos do ${ }^{182} \mathrm{Ta}$, da ordem de $10^{10}$ núcleos $/ \mathrm{cm}^{3}$, fato este esperado para irradiações de curto intervalo de tempo. Outro fator importante é a sua meia-vida de 5,1 dias ${ }^{[21]}$, o que fez com que sua atividade não interferisse nas medidas das amostras de ${ }^{182} \mathrm{Ta}$. 


\subsubsection{Preparação das fontes de ${ }^{182}$ Ta}

Após a irradiação, o pó metálico foi misturado em água destilada e gotas da mistura foram depositadas, com o auxílio de uma micropipeta, nos substratos de Collodion, preparados conforme descrito no item 2.3.1. Em seguida as fontes foram postas para secar sob irradiação de uma lâmpada de infravermelho. Após a secagem, foi colocado sobre a fonte um filme de Collodion já metalizado para evitar perda de material radioativo.

\subsection{Esquema de decaimento do ${ }^{182}$ Ta.}

O ${ }^{182}$ Ta decai com uma meia-vida de $114,43(0,03)$ dias ${ }^{[21]}$ por emissão de partículas $\beta^{-}$populando os níveis excitados do ${ }^{182} \mathrm{~W}$ originando a emissão de radiações gamas e/ou emissão de elétrons de conversão interna, no intervalo de energia de $31 \mathrm{keV}$ à $1453 \mathrm{keV}$. Na FIG.2.6 é apresentado o esquema de decaimento. Nas TAB.2.1 e TAB.2.2 são apresentados os valores das energias, intensidades e coeficientes de conversão interna das transições gama e das energias máximas e intensidades dos betas emitidos, respectivamente. 


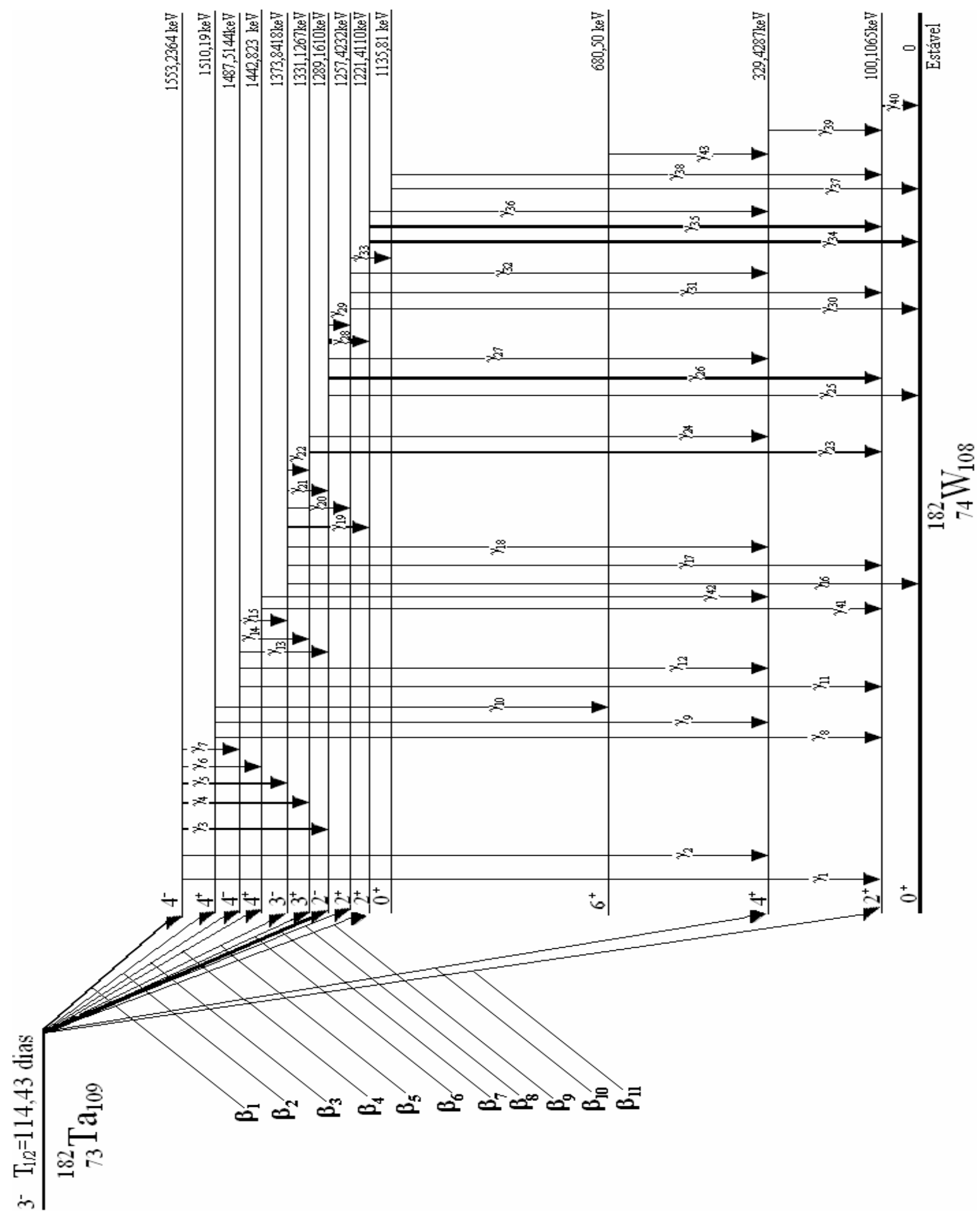

FIGURA 2.6 Esquema de decaimento do ${ }^{182} \mathrm{Ta}^{[21]}$. 
TABELA 2.1 Energias e intensidades gama e seus respectivos coeficientes de conversão interna.

\begin{tabular}{|c|c|c|c|c|c|}
\hline \multirow{2}{*}{$\begin{array}{c}\text { Transição } \\
\gamma\end{array}$} & \multirow{2}{*}{$\begin{array}{c}\text { Energia } \gamma \\
(\mathrm{keV})\end{array}$} & \multirow{2}{*}{$\begin{array}{l}\text { Intensidade } \\
\text { Absoluta }^{[21]}\end{array}$} & \multicolumn{3}{|c|}{ Coeficiente de conversão interna ${ }^{[16]}$} \\
\hline & & & $\alpha_{K}$ & $\alpha_{L}$ & $\alpha_{T}$ \\
\hline$\gamma_{29}$ & $31,7378(7)$ & $0,486(11)$ & $*$ & 1,28 & 1,5744 \\
\hline$\gamma_{22}$ & $42,7151(4)$ & $0,2775(59)$ & $*$ & $0,33(7)$ & $0,33(7)$ \\
\hline$\gamma_{7}$ & $65,72201(18)$ & $2,925(68)$ & $*$ & $2,45(15)$ & $3,04(45)$ \\
\hline$\gamma_{28}$ & $67,75001(19)$ & $41,22(71)$ & $*$ & $0,17(2)$ & $0,211(35)$ \\
\hline$\gamma_{21}$ & $84,68080(24)$ & $2,645(67)$ & $5,0(7)$ & $1,39(25)$ & $6,8(2,0)$ \\
\hline$\gamma_{40}$ & $100,1065(3)$ & $14,10(26)$ & $0,76(5)$ & $2,09(14)$ & 3,3574 \\
\hline$\gamma_{6}$ & $110,41(5)$ & $0,0869(38)$ & $*$ & $*$ & $*$ \\
\hline$\gamma_{15}$ & $113,6725(3)$ & $1,885(37)$ & $2,3(3)$ & $0,489(67)$ & $2,93(67)$ \\
\hline$\gamma_{20}$ & $116,4186(7)$ & $0,4307(89)$ & 0,2 & 10 & 10,2 \\
\hline$\gamma_{33}$ & $121,5(2)$ & $0,0026(7)$ & $*$ & $*$ & $*$ \\
\hline$\gamma_{19}$ & $152,4308(3)$ & $6,93(13)$ & $0,094(6)$ & $0,0181(12)$ & 0,1121 \\
\hline$\gamma_{14}$ & $156,3876(3)$ & $2,642(49)$ & $0,09(2)$ & $0,0138(31)$ & $0,104(24)$ \\
\hline$\gamma_{5}$ & $179,3945(3)$ & $2,925(54)$ & $0,49(3)$ & $0,144(15)$ & $1,26(26)$ \\
\hline$\gamma_{13}$ & $198,3532(3)$ & $1,441(28)$ & $0,16(2)$ & $0,114(22)$ & $0,31(11)$ \\
\hline$\gamma_{4}$ & $222,1096(4)$ & $7,49(14)$ & $0,039(5)$ & $0,0087(19)$ & $0,048(12)$ \\
\hline$\gamma_{39}$ & $229,3220(9)$ & $3,630(66)$ & $0,12(1)$ & $0,052(10)$ & $0,172(36)$ \\
\hline$\gamma_{3}$ & $264,0752(3)$ & $3,605(67)$ & $0,073(8)$ & $0,0332(70)$ & $0,106(12)$ \\
\hline$\gamma_{43}$ & $351,05(10)$ & $0,0091(11)$ & $*$ & $*$ & $*$ \\
\hline$\gamma_{10}$ & $829,7(1)$ & $0,0154(59)$ & $*$ & $*$ & * \\
\hline$\gamma_{36}$ & $891,9800(19)$ & $0,0565(43)$ & 0,0041 & $*$ & 0,0041 \\
\hline$\gamma_{32}$ & $927,992(2)$ & $0,619(13)$ & 0,004 & $0,0008(1)$ & $0,00504(63)$ \\
\hline$\gamma_{27}$ & $959,7296(19)$ & $0,3483(77)$ & 0,0097 & $0,0018(3)$ & $0,0105(18)$ \\
\hline
\end{tabular}


TABELA 2.1-Energias e intensidades gama e seus respectivos coeficientes de conversão interna.

\begin{tabular}{cccccc}
\hline \hline Transição & Energia $\gamma$ & Intensidade & \multicolumn{3}{c}{ Coeficiente de conversão interna } \\
$\gamma^{[16]}$ & $(\mathbf{k e V})$ & Absoluta $^{[21]}$ & $\alpha_{\mathbf{K}}$ & $\alpha_{\mathbf{L}}$ & $\alpha_{\mathbf{T}}$ \\
\hline \hline$\gamma_{24}$ & $1001,6950(19)$ & $2,066(38)$ & 0,0036 & $*$ & 0,0043 \\
$\gamma_{38}$ & $1035,8(2)$ & $0,0073(24)$ & $*$ & $*$ & $*$ \\
$\gamma_{18}$ & $1044,4099(19)$ & $0,2366(58)$ & 0,0043 & $*$ & 0,0043 \\
$\gamma_{42}$ & $1113,40(5)$ & $0,4457(9)$ & 0,0051 & $*$ & 0,0028 \\
$\gamma_{35}$ & $1121,3008(17)$ & $34,90(61)$ & 0,003 & $*$ & 0,003 \\
$\gamma_{37}$ & $1135,9(2)$ & $0,00006(1)$ & $*$ & $*$ & $*$ \\
$\gamma_{31}$ & $1157,3127(18)$ & $0,59(11)$ & $*$ & $*$ & 0,0028 \\
$\gamma_{12}$ & $1158,0817(19)$ & $0,401(60)$ & $*$ & $*$ & $*$ \\
$\gamma_{9}$ & $1180,78(10)$ & $0,0855(51)$ & $*$ & $*$ & $*$ \\
$\gamma_{26}$ & $1189,0503(17)$ & $16,23(28)$ & 0,00396 & $*$ & 0,00396 \\
$\gamma_{34}$ & $1221,4066(17)$ & $26,98(48)$ & 0,00253 & $*$ & 0,00253 \\
$\gamma_{2}$ & $1223,8033(19)$ & $0,23(8)$ & $*$ & $*$ & $*$ \\
$\gamma_{23}$ & $1231,0157(17)$ & $11,44(20)$ & 0,0025 & $*$ & 0,0025 \\
$\gamma_{30}$ & $1257,4185(18)$ & $1,488(26)$ & 0,0022 & $*$ & 0,0022 \\
$\gamma_{17}$ & $1273,7305(17)$ & $0,651(11)$ & 0,0026 & $*$ & 0,0026 \\
$\gamma_{25}$ & $1289,1561(17)$ & $1,349(24)$ & 0,0088 & $*$ & 0,0088 \\
$\gamma_{41}$ & $1342,72(5)$ & $0,2513(45)$ & 0,0021 & $*$ & 0,0021 \\
$\gamma_{16}$ & $1373,8363(17)$ & $0,2185(40)$ & 0,0039 & $*$ & 0,0039 \\
$\gamma_{11}$ & $1387,4022(17)$ & $0,0708(15)$ & 0,0039 & $*$ & 0,0039 \\
$\gamma_{8}$ & $1410,10(17)$ & $0,0394(12)$ & 0,003 & $*$ & 0,0030 \\
$\gamma_{1}$ & $1453,1237(17)$ & $0,0284(9)$ & 0,0026 & $*$ & 0,0026 \\
\hline \hline & & $*$ & & $*$ \\
\hline
\end{tabular}

*não encontrado na literatura. 
TABELA 2.2 Energia máxima dos betas emitidos e suas respectivas intensidades ${ }^{[21]}$.

\begin{tabular}{ccc}
\hline & $\begin{array}{c}\text { Energia máxima } \\
(\mathbf{k e V})\end{array}$ & $\begin{array}{c}\text { Intensidade } \\
(\%)\end{array}$ \\
\hline \hline$\beta_{1}$ & 260,3636 & 29,3 \\
$\beta_{2}$ & 303,41 & 0,125 \\
$\beta_{3}$ & 326,0856 & 1,8 \\
$\beta_{4}$ & 0,00587 & 0,587 \\
$\beta_{5}$ & 439,7582 & 20,5 \\
$\beta_{6}$ & 482,4733 & 2,20 \\
$\beta_{7}$ & 524,439 & 39,7 \\
$\beta_{8}$ & 556,1768 & 0,88 \\
$\beta_{9}$ & 592,189 & 4,0 \\
$\beta_{10}$ & 1484,1713 & 0,096 \\
$\beta_{11}$ & 1713,4935 & 0,058 \\
\hline \hline
\end{tabular}

\subsection{Simulação de Monte Carlo}

O método de Monte Carlo é um método estatístico utilizado em simulações estocásticas com aplicações em diversas áreas do conhecimento, como por exemplo, a física e a matemática. Este método baseia-se no uso de números aleatórios e estatística de probabilidades a fim de obter uma aproximação numérica da função de interesse. Atualmente o método de Monte Carlo utiliza algoritmos aplicados em computadores para a geração dos números aleatórios ${ }^{[11,12]}$.

No presente trabalho, foram realizadas algumas simulações com base no método de Monte Carlo, para a obtenção e observação do comportamento da curva de extrapolação da atividade versus o parâmetro de ineficiência. Este programa, 
denominado ESQUEMA, foi desenvolvido no próprio $\mathrm{LMN}^{[22]}$, a fim de comparar o comportamento predito com os dados experimentais e também auxiliar na determinação das condições e procedimentos experimentais. Deste modo, pode-se predizer melhores condições de medidas a serem realizadas para um determinado radionuclídeo, o que faz economizar tempo, pois experimentalmente não se conseguiria tais informações tão brevemente.

A simulação utiliza o código de Monte Carlo MCNP4C (Monte Carlo N-Particle Transport Code System $)^{[23]}$ e incorpora em seus arquivos de dados todas as características do sistema de detecção $4 \pi(\mathrm{PC})-\mathrm{NaI}(\mathrm{Tl})$ e diversas informações como o próprio esquema de decaimento do radionuclídeo em estudo.

O programa ESQUEMA ${ }^{[22]}$ utilizado no presente trabalho faz uso de cinco arquivos de entrada permanentes, três arquivos de entrada configuráveis e dois arquivos de saída, onde são apresentados os resultados da simulação. Os arquivos de entrada configuráveis são:

\section{$>$ Constant.dat \\ $>$ Esquema.dat \\ $>$ Npicos.dat}

No arquivo Constant.dat são descritas informações que caracterizam a medida que se quer simular, portanto neste arquivo são colocadas informações referentes a:

* Energia de discriminação na via beta;

Número de canais do multicanal que está utilizando;

Número de histórias (eventos);

Espessura mínima e máxima de absorvedores;

* Número de intervalos destes absorvedores;

* Resolução em energia do detector gama;

* Raio da arandela da fonte. 
No arquivo Esquema.dat são fornecidas as informações que caracterizam o radionuclídeo em estudo ${ }^{[22]}$, isto é, os dados do esquema de desintegração:

* Número atômico do elemento;

Número de níveis de energia do esquema de decaimento a serem populados;

* Energia de desintegração;

* Intensidades normalizadas dos ramos beta;

* Intensidades normalizadas dos ramos gama;

* Matriz dos coeficientes de conversão interna total;

Matriz dos coeficientes de conversão interna da camada K;

* Probabilidades de emissão de raio X nas camadas K e L.

No arquivo Npicos.dat são selecionados os intervalos de energias gama que irão formar os eventos coincidentes com as partículas beta. Tal seleção é feita por meio dos intervalos de canais em que se forma o espectro gama dado pelo próprio programa.

Os arquivos de saída utilizados são:

MCBG.out

$>$ NBGC.out

$\mathrm{O}$ arquivo MCBG.out fornece informações do programa referente a uma dada simulação:

* Dados de entrada lidos pelo programa;

- Matriz do espectro beta;

Matrizes com as contagens no canal beta, gama e coincidência;

Total de números aleatórios gerados;

Tempo de processamento. 
O arquivo NBGC.out fornece ao usuário os resultados das simulações obtidas por meio do método de Monte Carlo. Neste arquivo é apresentado:

A variação da espessura dos absorvedores;

* O parâmetro $\mathrm{N}_{\beta} \mathrm{N}_{\gamma} / \mathrm{N}_{\mathrm{c}}$;

* A incerteza em porcentagem do parâmetro $\mathrm{N}_{\beta} \mathrm{N}_{\gamma} / \mathrm{N}_{c}$;

* Parâmetro de ineficiência $\left(1-\mathrm{N}_{\mathrm{c}} / \mathrm{N}_{\gamma}\right) / \mathrm{N}_{\mathrm{c}} / \mathrm{N}_{\gamma}$ em função de uma dada espessura de absorvedor.

Detalhes do arquivos permanentes podem ser obtidos na referência 22 .

O programa efetua uma simulação do espectro de coincidências obtido no sistema $4 \pi(\mathrm{PC})-\mathrm{NaI}(\mathrm{Tl})$ e também um espectro gama obtido por meio do detector $\mathrm{NaI}(\mathrm{Tl})$, para que assim possa ser escolhido um intervalo de energia gama. Na FIG.2.7 é mostrado o espectro gama obtido pela simulação de Monte Carlo e na FIG.2.8 é mostrado o espectro obtido experimentalmente.

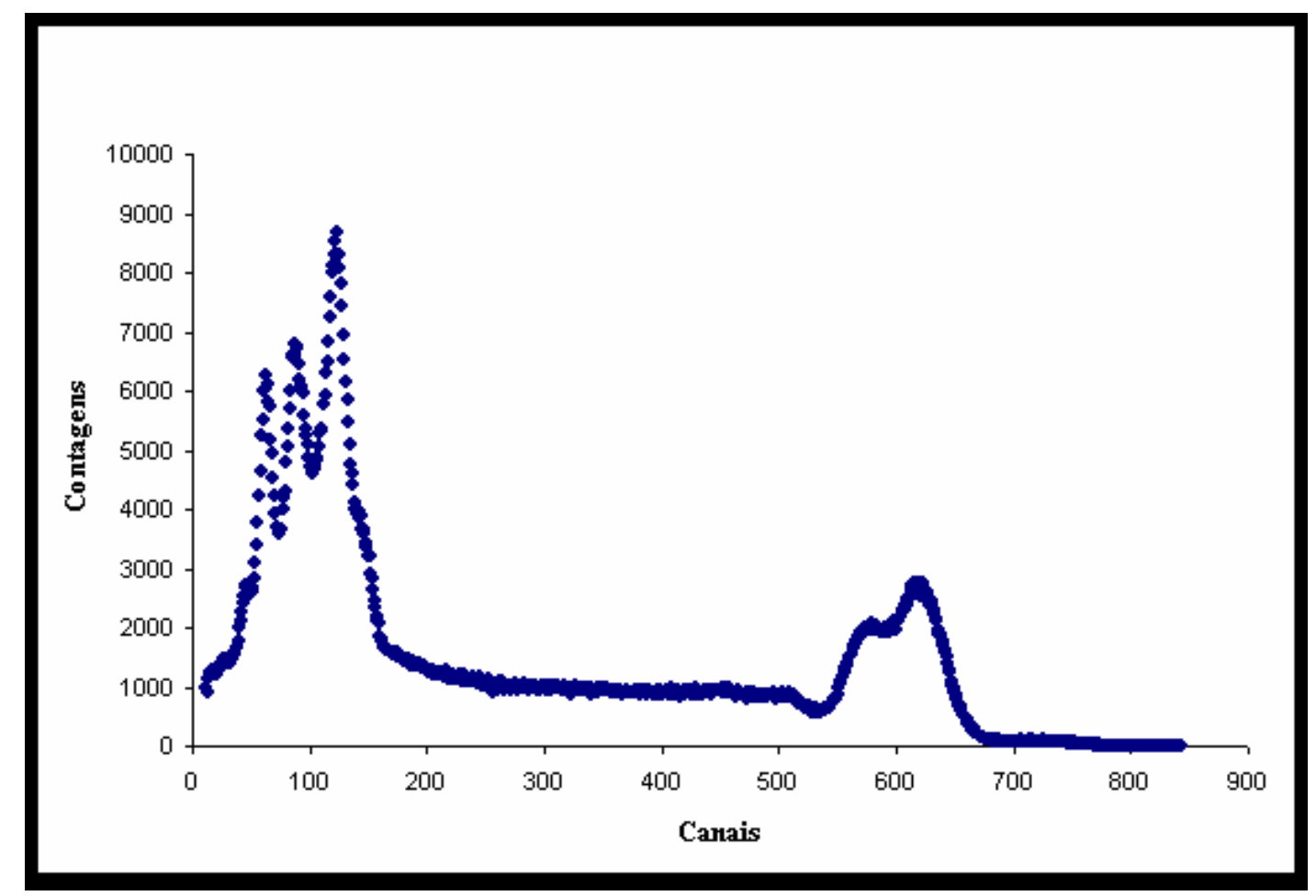

FIGURA 2.7 Espectro gama obtido por meio da simulação em Monte Carlo. 


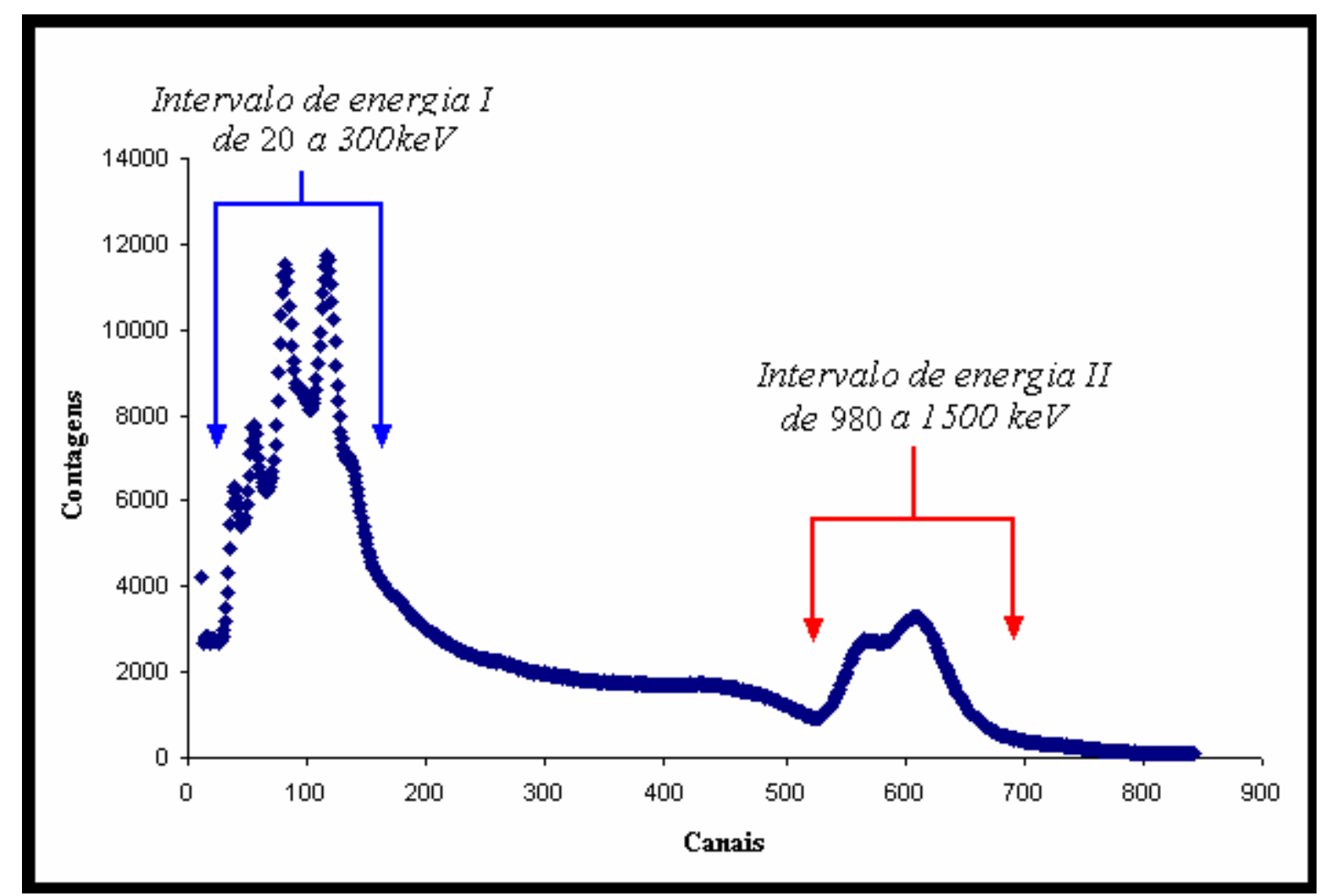

FIGURA 2.8 - Espectro gama obtido experimentalmente.

Como pode ser observado a simulação e o espectro real são coincidentes, com exceção na região de baixa energia. 


\section{DETERMINAÇÃO DAS PROBABILIDADES DE EMISSÃO $\gamma$ POR DECAIMENTO DO ${ }^{182} \mathrm{Ta}$}

Para se determinar a probabilidade de emissão gama por decaimento do ${ }^{182} \mathrm{Ta}$, além do conhecimento da atividade, foi utilizado um sistema de medida com um detector semicondutor de germânio hiperpuro (HPGe).

Essa escolha se deve às diversas vantagens do detector de germânio em relação a outros tipos, sua principal característica é a sua resolução em energia da ordem de 2 $\mathrm{keV}$ que em espectroscopia gama se faz muito necessário, permitindo a identificação de um grande número de fótons emitidos com energias relativamente próximas, detalhes estes que não podem ser obtidos com um cristal cintilador.

\subsection{Detector de HPGe ou Germânio Intrínseco}

A passagem da radiação por um material semicondutor com estruturas de bandas provoca a criação de um grande número de pares elétrons-lacunas ao longo da trajetória da partícula, que são coletados por meio de um campo elétrico aplicado no material. A energia média gasta para criar um par elétron-lacuna é denominada energia de ionização. A principal vantagem dos semicondutores reside na pouca energia necessária para gerar um par elétron-lacuna, em torno de $3 \mathrm{eV}$ para detectores de germânio $^{[11,12]}$, quando comparada com aquela necessária à criar um par de íons nos gases que é de aproximadamente $30 \mathrm{eV}$. O grande número de pares criado propicia duas vantagens aos detectores semicondutores sob o ponto de vista de resolução: diminui a flutuação estatística e a influência do ruído eletrônico, levando a uma melhor relação sinal-ruído. 
Sua eficiência é menor que a de um cristal cintilador de $\mathrm{NaI}(\mathrm{Tl})$ e diminui com o aumento da energia do fóton a ser estudado ${ }^{[11,12]}$.

A interação da radiação com o cristal pode-se dar preferencialmente pelo três processos já descrito no item 1.6.

No caso de uma interação fotoelétrica ou um espalhamento Compton seguido de uma interação fotoelétrica, tem-se no espectro um fotopico cuja energia corresponde basicamente a toda energia do fóton incidente no cristal de germânio, formando assim uma distribuição aproximadamente normal. Neste mesmo espectro pode-se observar um espectro contínuo proveniente das interações com perda parcial da energia dos fótons incidentes. Comumente sua geometria segue uma simetria cilíndrica ou coaxial.

\subsection{Sistema de espectroscopia gama}

O sistema de espectroscopia gama utilizado neste trabalho é constituído de um detector de germânio hiper puro modelo ReGe ( Reverse-electrode Ge detector) seguindo uma simetria coaxial, sua resolução é de $1,79 \mathrm{keV}$ para a energia de 1332 $\mathrm{keV}$ do ${ }^{60} \mathrm{Co}^{[24]}$, este detector possui uma janela de berílio de $0,2 \mu \mathrm{m}$ de espessura sendo seu diâmetro de $57,7 \mathrm{~mm}$ e seu comprimento de $41,5 \mathrm{~mm}$, com eficiência de $15 \%$ em relação ao $\mathrm{NaI}(\mathrm{Tl})$.

A distância fonte detector utilizada foi de 17,6 cm. A FIG.3.1 mostra o arranjo experimental, posicionado em uma blindagem de chumbo de $100 \mathrm{~cm} \times 100 \mathrm{~cm} \times 100 \mathrm{~cm}$ revestida internamente com materiais de números atômicos decrescente $(\mathrm{Cd}, \mathrm{Cu}, \mathrm{e}$ plástico) para minimizar a detecção dos raios X provenientes da interação da radiação gama com a blindagem ${ }^{[6]}$. 


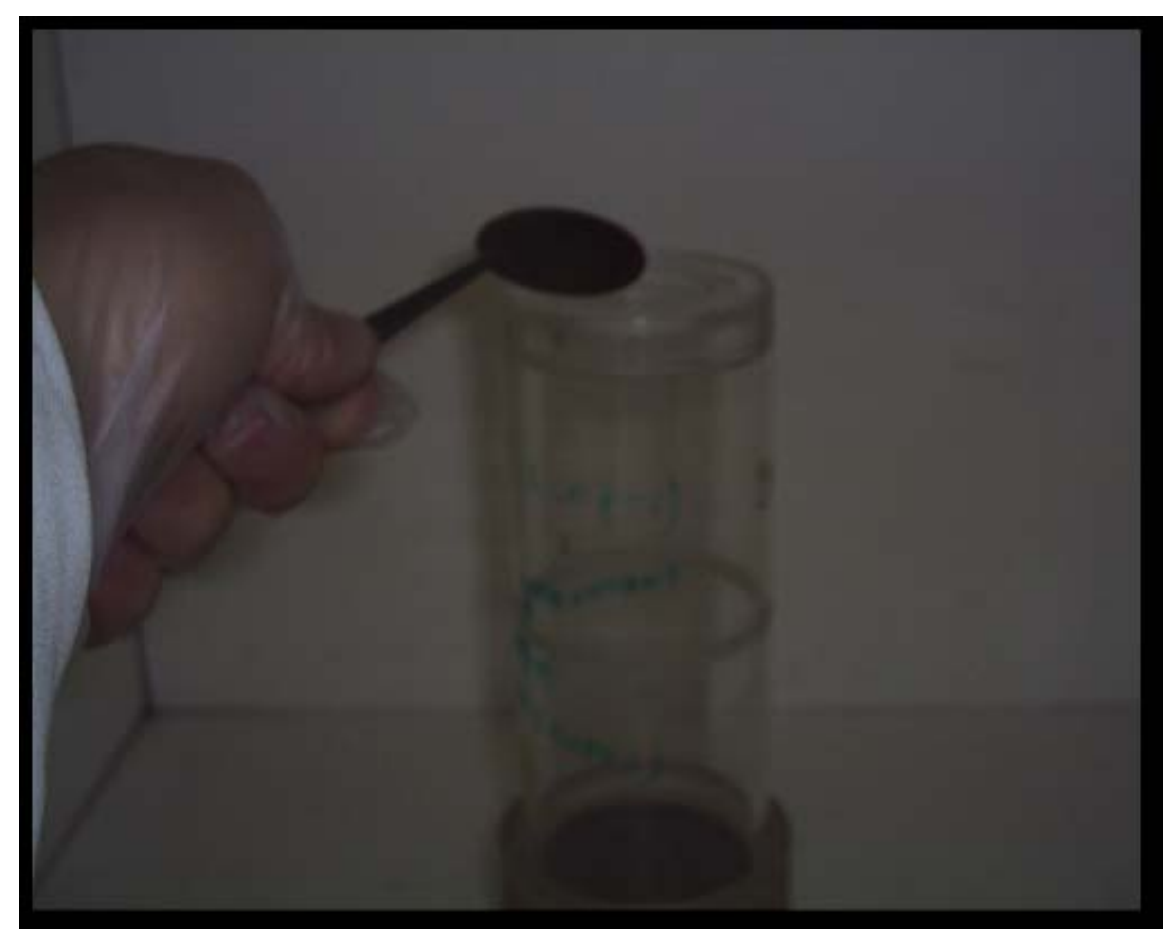

FIGURA 3.1 Fonte e suporte para fontes montadas sob o detector de HPGe.

O arranjo eletrônico utilizado, apresentado na FIG.3.2., é constituído de um amplificador, um pulsador para a correção do tempo morto, uma fonte de alta tensão, um amplificador e um multicanal (MCA) para o registro do espectro medido.

\subsection{Correções Aplicadas}

Correções são aplicadas nas áreas dos fotopicos de interesse em virtude das condições reais em que são realizadas as medidas. São elas: correção para a radiação de fundo (BG), correção para o tempo morto do sistema de detecção, correção para o efeito de auto absorção ou atenuação quando necessário, correção para geometria, quando as fontes em estudo diferem das fontes padrões utilizadas na determinação da curva de calibração e correção para o efeito soma em cascata. 


\subsubsection{Correção da radiação de fundo}

A radiação de fundo é proveniente de radiações cósmicas de alta energia e de radiações do ambiente que são subtraídas do espectro obtido. Para efetuar esta correção são medidos os espectros sem a fonte radioativa nas mesmas condições que foram efetuadas as medidas das fontes.

Além desta correção é feita a subtração das contribuições do continuo proveniente de efeitos não desejados tais como falhas na coleção, espalhamento Compton, etc.

A correção é feita por meio de uma integração numérica da área dos fotopicos em estudos em que é subtraída a área do espectro da radiação de fundo. A área correspondente à radiação de fundo é determinada pela somatória das contagens dos intervalos dos canais $\mathrm{C}_{\mathrm{i}}$ dada pela a equação 3.1.

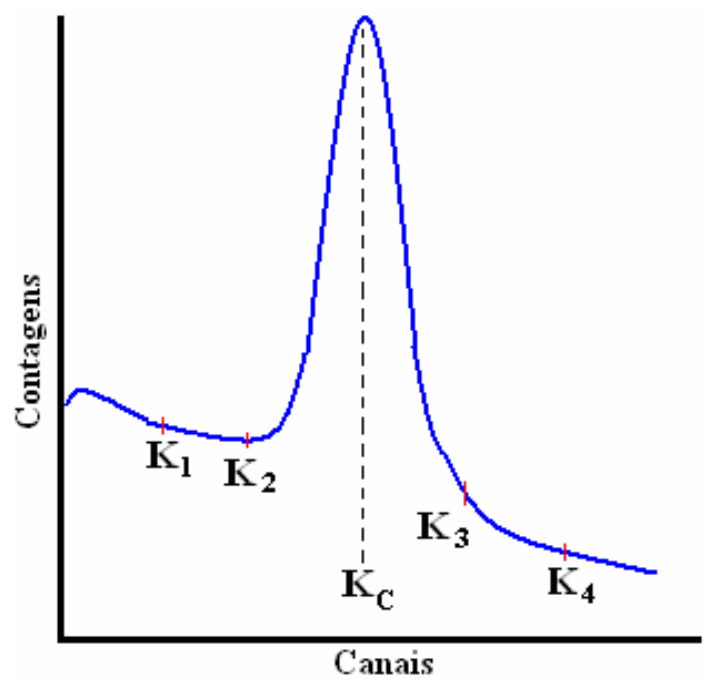

FIGURA 3.2 - Fotopico de absorção total de um sistema de HPGe.

$$
S_{B G}=\sum_{K_{1}}^{K_{2}} C_{i}+\sum_{K_{3}}^{K_{4}} C_{i}
$$


Onde:

$K_{1}=K_{c}-3 D$ é o canal de início de contagem da radiação de fundo.

$K_{2}=K_{C}-2 D$ é o canal de início do fotopico de absorção total.

$K_{3}=K c+2 D$ é o canal final do fotopico de absorção total.

$K_{4}=K_{c}+3 D$ é o canal final de contagem da radiação de fundo.

Sendo $K_{c}$ o canal da centróide do fotopico de absorção total e $D$ resolução do espectrômetro. Essa correção é feita por meio do programa ALPINO ${ }^{[27]}$.

\subsubsection{Correção para o efeito de auto-absorção, atenuação e geometria}

Fatores como alta densidade, alto número atômico e espessura do material da fonte podem ocasionar auto-absorção e atenuação da radiação na própria fonte ou atenuação nos envoltórios, devendo portanto, ser aplicado um fator de correção para estes efeitos.

No presente trabalho, as fontes foram preparadas em filmes finos de Collodion, desta forma, somente a atenuação no filme de Collodion foi corrigida, considerando-se não haver auto-absorção na fonte.

Com relação à correção do efeito geométrico, este foi considerado igual à 1 , uma vez que, como já mencionado as fontes possuem a mesma geometria.

\subsubsection{Correção do tempo morto}

Foi aplicado para a correção do tempo morto no sistema de detecção do HPGe o método do pulsador ${ }^{[2]}$. Neste método, um pulsador é ligado diretamente no préamplificador do sistema de deteç̧ão como indica a FIG.3.3. O pulsador envia pulsos para o pré-amplificador numa freqüência preestabelecida de $60 \mathrm{~Hz}$. Seu ganho assume 
um valor de maneira que ocupe uma posição no final do espectro, para que desta forma não se sobreponha a nenhum fotopico em estudo. O fator de correção é dado por:

$$
f_{\tau}=\frac{S_{p m}}{S_{p r}}
$$

Onde:

$\mathrm{S}_{\mathrm{pm}} \quad$ é a área sob o pico do pulsador no espectro de medida.

$\mathrm{S}_{\mathrm{pr}} \quad$ é a taxa real de contagens do pulsador, 60 cont/s.

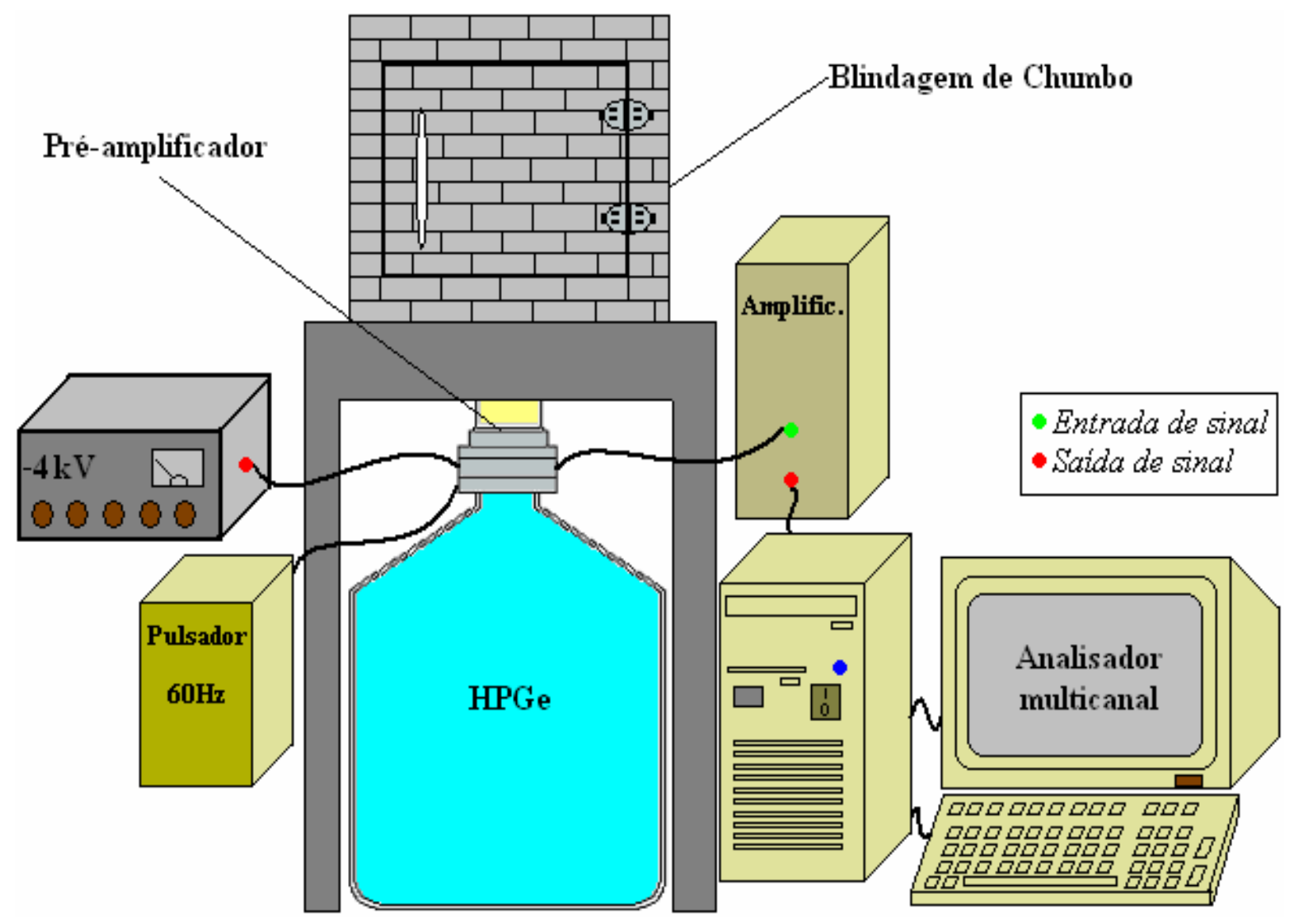

FIGURA 3.3 - Esquema do sistema de detecção para as medidas dos espectros gama. 


\subsubsection{Correção para efeito soma em cascata}

O tempo de transição entre os níveis excitados de um dado radionuclídeo pode variar de milhões de anos (estados isoméricos) a femtosegundos, fato este que pode ser observado quando há uma diferença muito grande de momento angular, entre o estado excitado e os estados inferiores energeticamente acessíveis, diminuindo a probabilidade de transição e conseqüentemente aumentando a vida média de emissão do fóton ${ }^{[5]}$.

No caso do ${ }^{182} \mathrm{~W}$ as transições possuem um tempo de vida média extremante curto, algumas da ordem de picosegundos, e seu esquema de decaimento possui diversos gamas (decaimento em cascata) o que pode acarretar o surgimento do efeito soma. Este efeito ocorre quando a vida média da transição, comparada com o tempo de resolução do sistema de detecção for muito pequena, pode-se dizer que a transição é simultânea, pois na prática os fótons emitidos em cascata são coincidentes e ao interagir no detector poderão ser interpretados como um único fóton. Se o número desses eventos coincidentes for suficientemente grande para a formação de um fotopico no espectro, surgirá um pico-soma, cuja energia corresponde a soma de duas transições distintas e os picos correspondentes à energia dos fótons sofrerão perdas.

Este efeito se torna maior com o aumento dos fatores de eficiência de detecção, portanto aumentando-se à distância fonte-detector e/ou utilizando-se detectores com um menor volume sensível, pode-se diminuir as ocorrências deste efeito. Como o efeito soma é a coincidência entre dois gamas em cascata, ou seja, de um mesmo núcleo, tal fenômeno não possui nenhuma relação com a atividade da fonte em questão, podendo ocorrer mesmo para baixas taxas de contagens.

A correção para o efeito soma foi determinada por meio do programa COINCIG

${ }^{[25]}$, desenvolvido no LMN. Neste programa, os fatores de correção são obtidos por meio de uma simulação da emissão de fótons em cascatas que possivelmente formariam a coincidência entre os gamas de acordo com o esquema de decaimento do radionuclídeo. Na TAB.3.1 é apresentado o fator de correção utilizado na correção 
deste efeito para cada uma das energias gama das fontes padrões e na TAB. 3.2 é apresentado o fator de correção utilizado na correção do efeito soma para cada uma das energias gama do ${ }^{182} \mathrm{Ta}$.

TABELA 3.1 - Correção na eficiência para o efeito soma para as fontes padrões.

\begin{tabular}{ccc}
\hline \hline Energia $\gamma$ & Correção & Incerteza (\%) \\
\hline \hline $\mathbf{1 2 1 , 7 8}$ & 0,9913793 & 0,009 \\
$\mathbf{2 4 4 , 7 0}$ & 0,9894702 & 0,024 \\
$\mathbf{3 4 4 , 2 8}$ & 0,9961903 & 0,005 \\
$\mathbf{4 1 1 , 1 3}$ & 0,9938802 & 0,024 \\
$\mathbf{4 4 3 , 9 6}$ & 0,9953036 & 0,029 \\
$\mathbf{7 7 8 , 9 0}$ & 0,9952896 & 0,012 \\
$\mathbf{8 6 7 , 3 9}$ & 0,9947317 & 0,023 \\
$\mathbf{9 6 4 , 0 5}$ & 0,9953419 & 0,031 \\
$\mathbf{1 1 1 2 , 0 9}$ & 0,9951932 & 0,011 \\
$\mathbf{1 4 0 8 , 0 2}$ & 0,9952049 & 0,009 \\
$\mathbf{5 9 , 5 4}$ & 0,9994619 & 0,010 \\
$\mathbf{8 0 , 9 0}$ & 0,9915985 & 0,009 \\
$\mathbf{2 7 6 , 4 0}$ & 0,9948148 & 0,031 \\
$\mathbf{3 0 2 , 8 5}$ & 0,9942167 & 0,013 \\
$\mathbf{3 5 6 , 0 2}$ & 0,99518 & 0,005 \\
$\mathbf{3 8 3 , 8 5}$ & 0,9960566 & 0,016 \\
$\mathbf{1 1 7 3 , 2 4}$ & 0,9974146 & 0,050 \\
$\mathbf{1 3 3 2 , 5 0}$ & 0,9973918 & 0,050 \\
$\mathbf{8 0 , 5 8}$ & 0,9904090 & 0,025 \\
$\mathbf{1 8 4 , 4 1}$ & 0,9916407 & 0,006 \\
$\mathbf{2 8 0 , 4 5}$ & 0,9911239 & 0,020 \\
$\mathbf{4 1 0 , 9 4}$ & 0,9907549 & 0,002 \\
$\mathbf{5 2 9 , 8 1}$ & 0,9884183 & 0,087 \\
$\mathbf{5 7 1 , 0 0}$ & 0,9917338 & 0,002 \\
$\mathbf{7 1 1 , 6 9}$ & 0,9919191 & 0,001 \\
$\mathbf{7 5 2 , 0 0}$ & 0,9918094 & 0,002 \\
$\mathbf{8 1 0 , 3 1}$ & 0,9920761 & 0,001 \\
\hline & & \\
\hline
\end{tabular}


TABELA 3.2 - Correção na eficiência para o efeito soma para a fonte de ${ }^{182} \mathrm{Ta}$.

\begin{tabular}{ccc}
\hline Energia $\gamma$ & Correção & Incerteza (\%) \\
\hline $\mathbf{8 4 , 6 8}$ & 0,9907576 & 0,120 \\
$\mathbf{1 0 0 , 1 1}$ & 0,9932724 & 0,006 \\
$\mathbf{1 5 2 , 4 3}$ & 0,9939541 & 0,006 \\
$\mathbf{1 5 6 , 3 9}$ & 0,9939362 & 0,026 \\
$\mathbf{1 7 9 , 3 9}$ & 1 & 0 \\
$\mathbf{2 2 2 , 1 1}$ & 1 & 0 \\
$\mathbf{2 2 9 , 3 2}$ & 1 & 0 \\
$\mathbf{2 6 4 , 0 8}$ & 1 & 0 \\
$\mathbf{1 0 0 1 , 7 0}$ & 0,9924627 & 0,010 \\
$\mathbf{1 1 2 1 , 3 0}$ & 0,9913485 & 0,006 \\
$\mathbf{1 1 8 9 , 0 5}$ & 1,011953 & 0,028 \\
$\mathbf{1 2 2 1 , 4 1}$ & 0,9941353 & 0,006 \\
$\mathbf{1 2 3 1 , 0 2}$ & 09950048 & 0,003 \\
$\mathbf{1 2 5 7 , 4 2}$ & 0,9940056 & 0,029 \\
\hline \hline
\end{tabular}

\subsection{Calibração do espectrômetro HPGe}

A curva de calibração do espectrômetro gama com detector semicondutor HPGe foi determinada pela medida de fontes em substratos de Collodion de ${ }^{152} \mathrm{Eu},{ }^{241} \mathrm{Am}$, ${ }^{133} \mathrm{Ba},{ }^{60} \mathrm{Co}$ e ${ }^{166 \mathrm{~m}} \mathrm{Ho}$ cujas atividades foram determinadas pelo sistema $4 \pi(\mathrm{PC})-\mathrm{NaI}(\mathrm{Tl})$, a medida dos espectros foram feitas em um tempo real da ordem de $10^{5}$ segundos. $\mathrm{Na}$ TAB.3.2 são apresentadas informações sobre estes nuclídeos como meia-vida, energia, intensidade de transição gama, atividade e data de referência. 
TABELA 3.3- Dados das fontes padrões utilizadas para a obtenção da curva de calibração.

\begin{tabular}{|c|c|c|c|c|c|}
\hline Radionuclídeo & $\begin{array}{c}\text { Meia-vida } \\
\quad \text { (dias) }\end{array}$ & $\begin{array}{c}\text { Energia }^{[26]} \\
(\mathrm{keV})\end{array}$ & $\begin{array}{c}\text { Intensidade } \\
{ }^{[26]}(\%)\end{array}$ & $\begin{array}{c}\text { Atividade } \\
\text { (kBq) }\end{array}$ & $\begin{array}{c}\text { Data de } \\
\text { referência }\end{array}$ \\
\hline${ }^{152} \mathrm{Eu}$ & $4933(11)$ & $\begin{array}{c}121,7824(4) \\
344,2811(19 \\
411,126(3) \\
443.965(4) \\
778,903(6) \\
867,390(6) \\
964,055(4) \\
1112,087(6) \\
1408,022(4)\end{array}$ & $\begin{array}{c}28,37(13) \\
26,57(11) \\
2,238(10) \\
3,125(14) \\
12,97(6) \\
4,214(25) \\
14,63(6) \\
13,54(6) \\
20,85(9)\end{array}$ & $6,746(22)$ & 01/07/99 às 09:00h \\
\hline${ }^{241} \mathrm{Am}$ & $157850(240)$ & $59,537(1)$ & $36,0(4)$ & $2,921(409)$ & $30 / 11 / 2002$ às $21: 00 \mathrm{~h}$ \\
\hline${ }^{133} \mathrm{Ba}$ & $3862(15)$ & $\begin{array}{c}80,900 \\
276,398(1) \\
302,853(1) \\
356,017(2)\end{array}$ & $\begin{array}{c}36,77(30) \\
7,14(3) \\
18,30(6) \\
61,94(14)\end{array}$ & 12,225 & 01/8/2002 às 00:00h \\
\hline${ }^{60} \mathrm{Co}$ & $1925,5(5)$ & $\begin{array}{l}383,851(3) \\
1.173,2380 \\
1.332,5020\end{array}$ & $\begin{array}{c}8,90(3) \\
99,86(2) \\
99,98(1)\end{array}$ & $44,431(76)$ & 25/6/2002 às 00:00h \\
\hline${ }^{166 m} \mathrm{Ho}$ & $438000(65700)$ & $\begin{array}{c}80,6^{[2]} \\
184,4^{[2]} \\
280,46^{[2]} \\
410,96^{[2]} \\
529,83^{[2]} \\
571,00^{[2]} \\
711,70^{[2]} \\
810,29^{[2]}\end{array}$ & $\begin{array}{c}12,57(14)^{[2]} \\
71,34(96)^{[2]} \\
29,17(22)^{[2]} \\
11,25(9)^{[2]} \\
9,55(8)^{[2]} \\
5,43(6)^{[2]} \\
53,85(32)^{[2]} \\
56,93(40)^{[2]}\end{array}$ & $1,9256(40)$ & 28/2/1999 às 21:00h \\
\hline
\end{tabular}




\subsection{Análise dos espectros}

Para obter as eficiências de detecção, os espectros foram analisados pelo programa ALPINO ${ }^{[27]}$ desenvolvido no LMN e a curva de calibração em eficiência para a geometria de medida foi ajusta por um polinômio de sexto grau por meio do código LOGFIT ${ }^{[28]}$.

Na FIG.3.4 é apresentada a curva de calibração obtida por meio das medidas das fontes padrões, os valores das eficiências foram corrigidos pelo programa COINCIG. A partir da curva de calibração, foram determinadas as eficiências para as energias das transições gama de interesse.

As fontes de ${ }^{182} \mathrm{Ta}$ padronizadas no sistema $4 \pi(\mathrm{PC})-\mathrm{NaI}(\mathrm{Tl})$, foram medidas no sistema HPGe, de modo semelhante aos padrões. Os espectros obtidos foram analisados pelo programa ALPINO. As probabilidades de emissão gama por decaimento foram determinadas pela equação 1.22, descrita no item 1.09.

\subsubsection{Programa Logfit}

Por meio do programa LOGFIT são determinados os parâmetros da curva de calibração e assim, os valores das eficiências para uma dada transição. São utilizados dois arquivos para a determinação dos parâmetros da curva, o arquivo logf.dat e o arquivo logfor.out.

No arquivo logf.dat são informados dados de cada transição dos fotopicos medidos das fontes padrões com suas incertezas e suas respectivas correlações. Portanto, são informados o(a):

Número de fotopicos obtidos experimentalmente;

Grau do polinômio estimado;

Número de incertezas; 


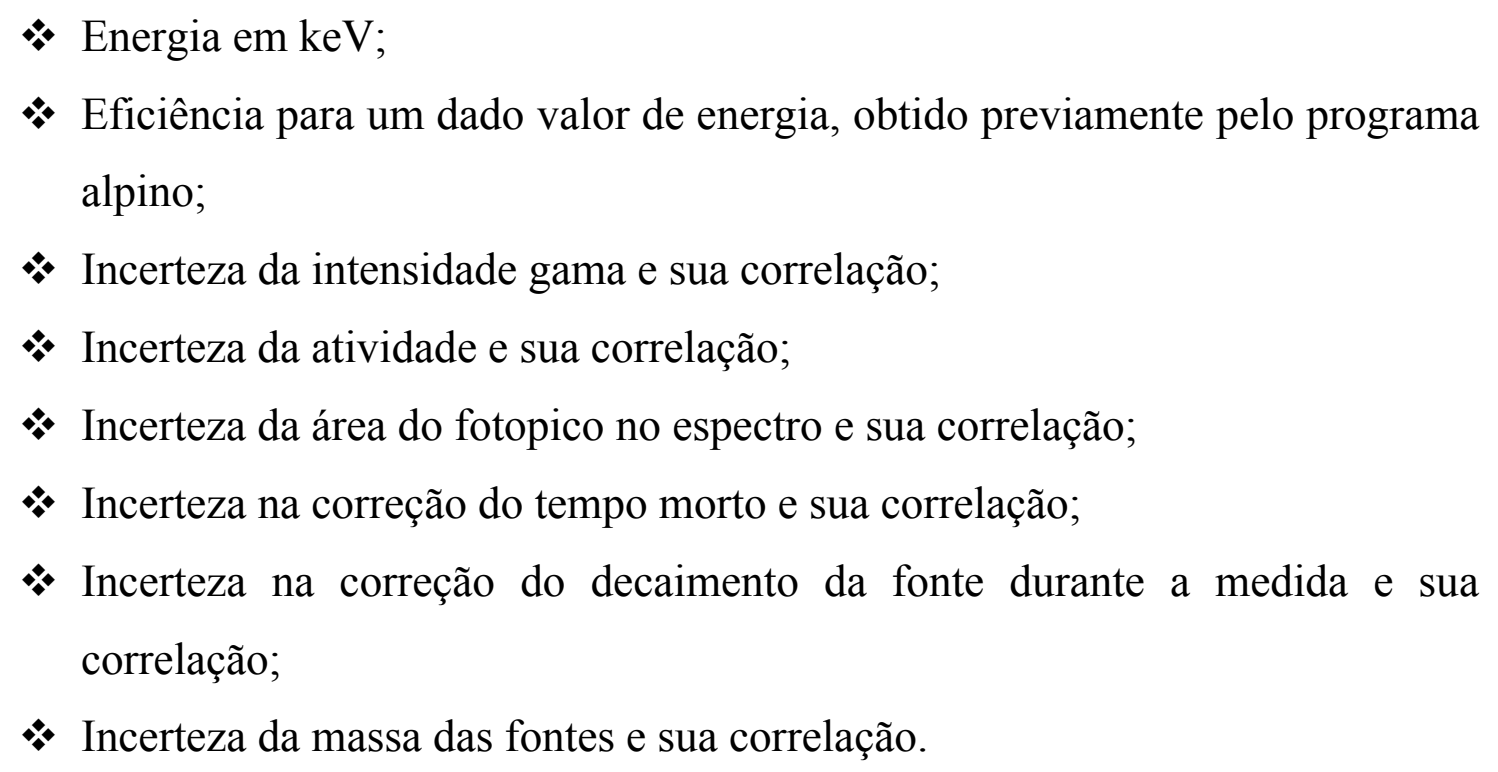

No arquivo de saída logfor.out, pode-se obter as informações referentes a curva de calibração de um dado sistema, portanto neste arquivo obtém-se:

Matriz de correlação das incertezas da eficiência;

Matriz de covariância dos parâmetros do ajuste;

* Parâmetros do ajuste e suas respectivas incertezas;

* Qui-quadrado reduzido;

* As eficiências para as energias de interesses e suas respectivas incertezas;

Matriz de correlação dos pontos de interpolação.

Os pontos apresentados em azul na FIG.3.4 representam os dados experimentais e a curva em vermelho desta mesma figura representa o ajuste teórico dado pelo programa. Esta curva de ajuste é regida por uma função logarítmica de sexto grau como a representada pela equação 3.3 cujos coeficientes são apresentados na TAB. 3.4.

$$
\ln \varepsilon(E)_{\gamma i}=\sum_{j=0}^{n} c_{j}\left(\ln E_{\gamma i}\right)^{j}
$$


A escolha do grau do polinômio foi feita através do ajuste que apresentou o melhor qui-quadrado reduzido $\left(\chi^{2}=1,63\right)$. Na TAB. 3.5 é apresentada a matriz da covariância dos parâmetros da curva de ajuste.

$\mathrm{Na}$ FIG.3.5 são apresentados os resíduos entre os valores obtidos experimentalmente e os fornecidos pela curva de calibração em eficiência.

TABELA 3.4 - Parâmetros da curva de ajuste e suas respectivas incertezas.

\begin{tabular}{cc}
\hline \hline Parâmetro & $\begin{array}{c}\text { Incerteza } \\
\text { absoluta }\end{array}$ \\
\hline \hline 234,3016 & 22,08 \\
$-226,0311$ & 20,17 \\
83,75914 & 7,295 \\
$-15,23121$ & 1,306 \\
1,358465 & 0,1157 \\
$-0,04767348$ & 0,004063 \\
\hline \hline
\end{tabular}

TABELA 3.5 - Matriz da covariância dos parâmetros da curva de ajuste.

\section{Matriz de correlação}

\begin{tabular}{llllll}
\hline \hline 487,62 & & & & & \\
$-445,313$ & 406,921 & & & & \\
160,888 & $-147,107$ & 53,2131 & & & \\
$-28,754$ & 26,3066 & $-9,52154$ & 1,70471 & & \\
2,54295 & $-2,32784$ & 0,843039 & $-0,15102$ & 0,0133868 & \\
$-0,08907$ & 0,081577 & $-0,02956$ & 0,005298 & $-0,00046992$ & 0,00001650490 \\
\hline \hline
\end{tabular}




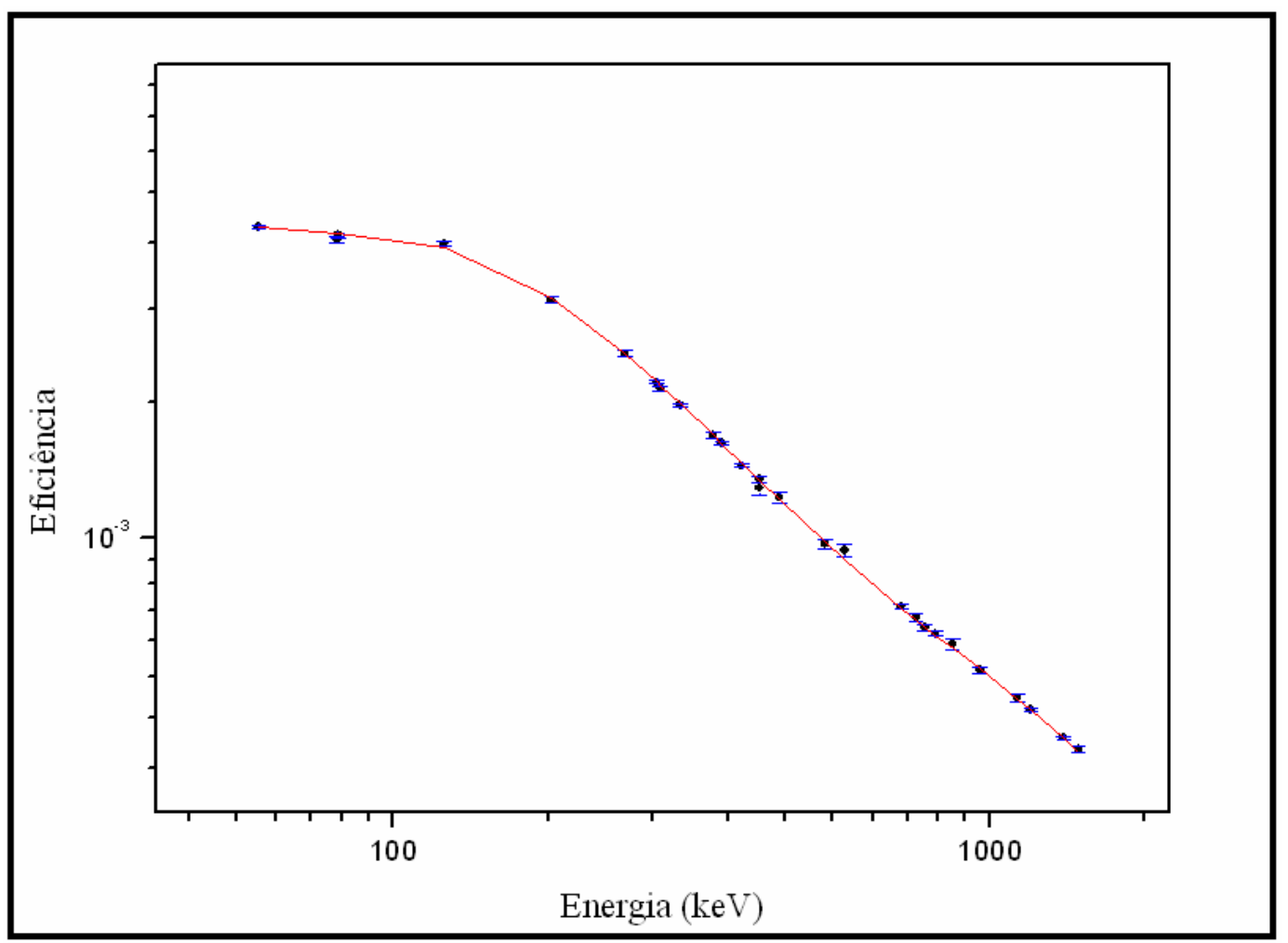

FIGURA 3.4 - Pontos experimentais e curva de ajuste para o sistema de HPGe.

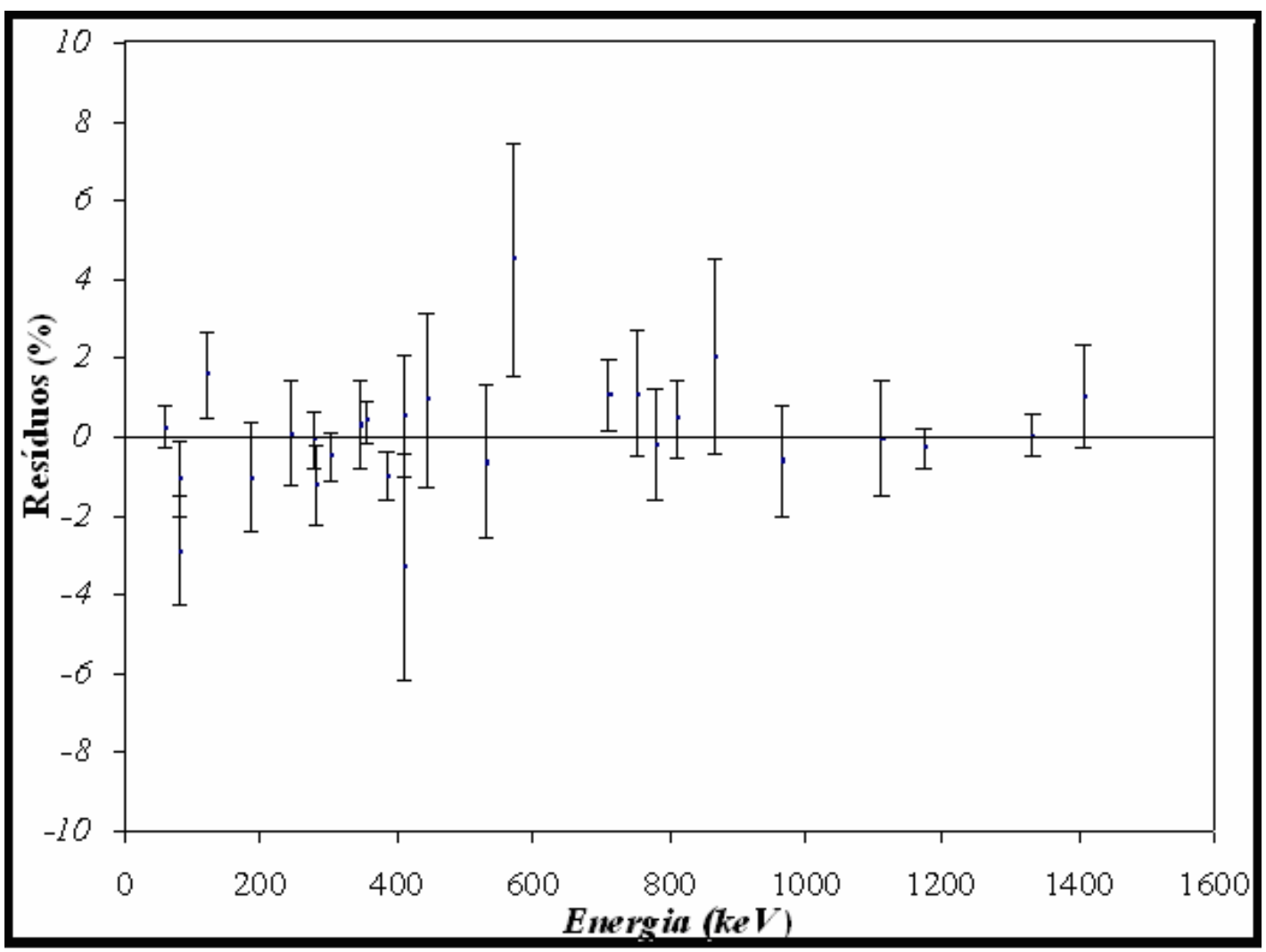

FIGURA 3.5- Curva dos resíduos entre os valores experimentais e os ajustados. 


\subsubsection{Programa ALPINO}

O programa ALPINO foi empregado para análise das áreas dos fotopicos em estudo, sua utilização é versátil podendo também determinar a eficiência de pico das energias gama dos padrões ou a atividade da fonte radioativa quando é fornecida a eficiência.

Para executar o programa, são utilizados dois arquivos o alpino.dat e o alpino.out.

No arquivo alpino.dat são informados dados da fonte radioativa medida e do sistema de detecção, como:

* Meia-vida do radionuclídeo em dias e sua incerteza em porcentagem;

* Atividade da fonte em becquerel e sua incerteza em porcentagem;

* Freqüência do pulsador utilizado em hertz;

Data e hora de referência da atividade da fonte;

* Coeficientes da curva de calibração em energia do multicanal;

* Número atômico, densidade em g. $\mathrm{cm}^{-3}$ e espessura em $\mathrm{cm}$ do material usado como suporte da fonte;

* Número atômico, densidade em g. $\mathrm{cm}^{-3}$ e espessura em $\mathrm{cm}$ da fonte;

Número de fotopicos a serem analisados;

* Energia, eficiência e os intervalos do fotopico em canal;

Número de canais;

* Tempo real da medida e tempo real da medida de radiação de fundo.

No arquivo de saída alpino.out é fornecido ao usuário informações como:

Eficiência de pico para as energias relacionadas;

* Atividade da fonte por energia gama e sua incerteza em porcentagem; 
* Atividade da fonte dada pela média aritmética das atividades de cada transição e sua incerteza em porcentagem.

Todas as correções aplicadas (item 3.3) estão incorporadas no programa.

A determinação das probabilidades de emissão gama por decaimento é feita por meio da razão entre área do pico para uma dada energia gama pela atividade da fonte determinada pelo sistema primário. 


\section{RESULTADOS E DiscussõES}

Neste capítulo são apresentados os resultados obtidos nas medidas das taxas de desintegração das fontes de ${ }^{182}$ Ta obtidas por meio dos dois intervalos de energia pelo método da coincidência e dos valores das probabilidades de emissão dos gamas mais intensos.

As medidas realizadas no sistema $4 \pi(\mathrm{PC})-\mathrm{NaI}(\mathrm{Tl})$ foram feitas em um tempo real de 2000 segundos e a radiação de fundo em um período de 1000 segundos.

\subsection{Medida no sistema $4 \pi \beta-\gamma$ pela técnica da extrapolação linear da eficiência}

Para a obtenção da taxa de desintegração do ${ }^{182}$ Ta foram utilizadas três fontes em substratos de Collodion que apresentavam a maior eficiência dentre as fontes confeccionadas no laboratório de acordo com os procedimentos descritos no item 2.3.3.

As medidas foram realizadas considerando dois intervalos de energias gama, o primeiro intervalo (gama I) foi de 20 a $300 \mathrm{keV}$, e o segundo intervalo (gama $I I$ ) de 980 a $1500 \mathrm{keV}$. Foram realizadas 9 medidas com um tempo real de 2000 segundos cada para uma primeira fonte, denominada fonte 1, a radiação de fundo foi medida com um tempo real de 1000 segundos após cada medida da fonte.

$\mathrm{Na}$ TAB.4.1 são apresentados os valores da ineficiência $\left(1-\mathrm{N}_{\mathrm{c}} / \mathrm{N}_{\gamma}\right) /\left(\mathrm{N}_{\mathrm{c}} / \mathrm{N}_{\gamma}\right)$ e atividade da fonte $1\left(\mathrm{~N}_{\beta} \cdot \mathrm{N}_{\gamma} / \mathrm{N}_{\mathrm{c}}\right)$ com suas respectivas incertezas, para os dois intervalos de energia gama. 
TABELA 4.1 Variação da atividade da fonte 1em função da variação da eficiência.

\begin{tabular}{cccc}
\hline \hline & Gama I & & Gama II \\
$\left(1-N_{c}\left(N_{\gamma}\right) /\left(N_{c} / N_{\gamma}\right)\right.$ & $N_{\beta} \cdot N_{\gamma} / N_{c}$ & $\left(1-N_{c}\left(N_{\gamma}\right) /\left(N_{c} / N_{\gamma}\right)\right.$ & $N_{\beta} N_{\gamma} / N_{c}$ \\
& $(\mathrm{kBq})$ & & $(\mathrm{kBq})$ \\
\hline \hline 0,0842 & $2,1436(32)$ & 0,1966 & $2,1093(57)$ \\
0,0953 & $2,1502(32)$ & 0,1356 & $2,1125(51)$ \\
0,1102 & $2,1634(35)$ & 0,1245 & $2,1079(44)$ \\
0,1226 & $2,1527(34)$ & 0,1178 & $2,1119(49)$ \\
0,1305 & $2,1529(34)$ & 0,1106 & $2,1151(49)$ \\
0,1455 & $2,1642(35)$ & 0,1045 & $2,1179(49)$ \\
0,1555 & $2,1658(45)$ & 0,0863 & $2,1169(47)$ \\
0,1719 & $2,1794(39)$ & 0,0773 & $2,1149(44)$ \\
0,2348 & $2,1766(41)$ & 0,0675 & $2,1106(44)$ \\
\hline \hline
\end{tabular}

Com os dados obtidos, pode-se obter o gráfico da FIG.4.1 onde tem-se $N_{\beta} N_{\gamma} / N_{c}$ em função de $\left(1-N_{d} / N_{\gamma}\right) /\left(N_{c} / N_{\gamma}\right)$ para os dois intervalos de energia considerados. A eficiência do detector beta variou de $92 \%$ a $81 \%$ para as medidas realizadas em gama $I$ e de $94 \%$ a $84 \%$ para as medidas realizadas em gama II. Os pontos em azul correspondem às medidas no intervalo gama $I$ e os pontos em vermelho correspondem às medidas no intervalo gama II. 


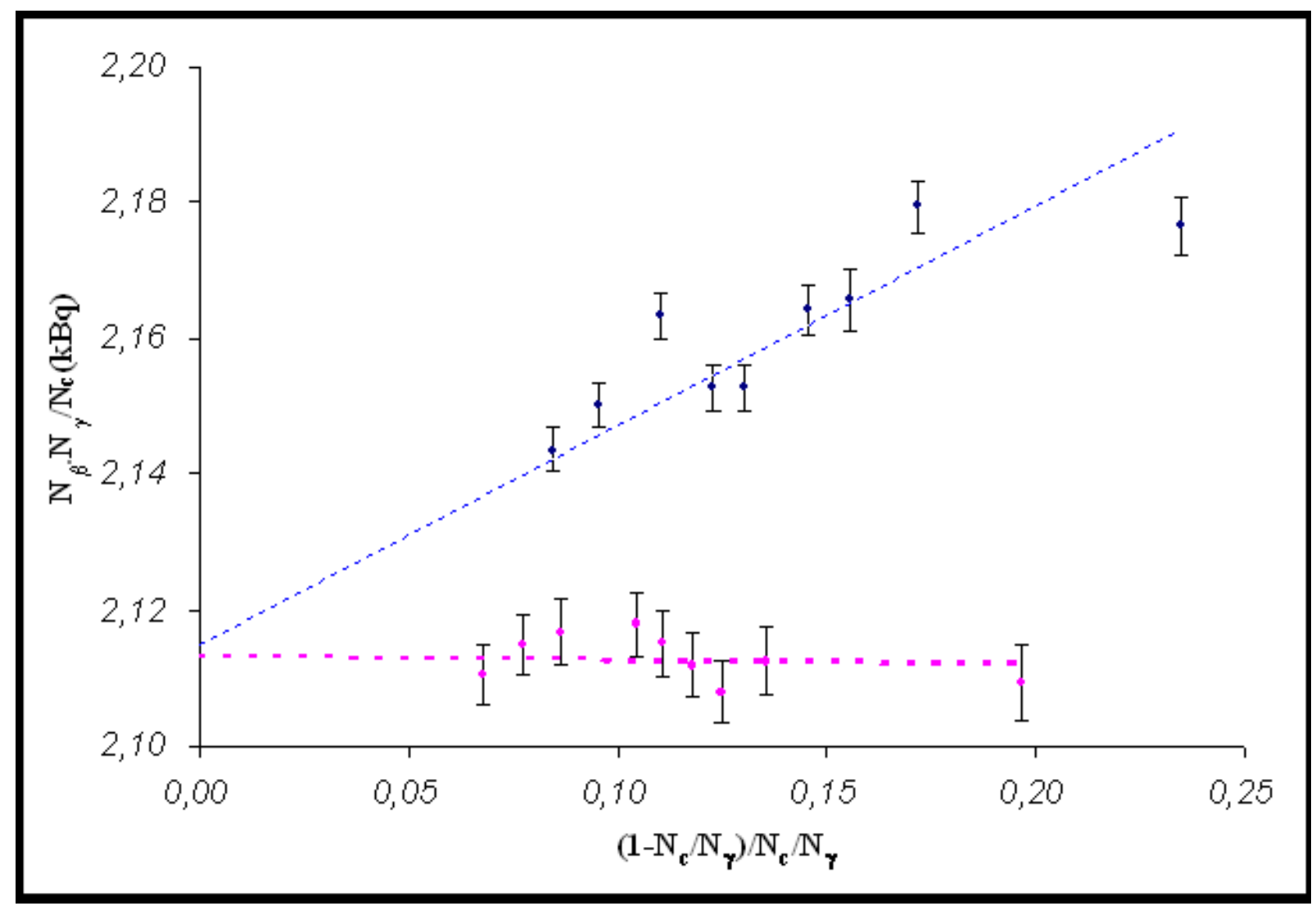

FIGURA 4.1 Curva de extrapolação para os dois intervalos de energia $\gamma$ para a fonte 1 .

Para a fonte 2 foram realizadas 22 medidas com um tempo real de 2000 segundos cada. $\mathrm{Na}$ TAB.4.2 são apresentados os valores da ineficiência $\left(1-N_{c} / N_{\gamma}\right) /\left(N_{c} / N_{\gamma}\right)$ e atividade obtidas $\left(N_{\beta} N_{\gamma} / N_{c}\right)$ com suas respectivas incertezas, para os dois intervalos de energia gama. 
TABELA 4.2 Variação da atividade da fonte 2 em função da variação da eficiência.

\begin{tabular}{|c|c|c|c|}
\hline \multicolumn{2}{|c|}{ Gama I } & \multicolumn{2}{|c|}{ Gama II } \\
\hline$\left(1-N_{d} / N_{\gamma}\right) /\left(N_{d} / N_{\gamma}\right)$ & $\begin{array}{r}N_{\beta} N_{\gamma} / N_{c} \\
(\mathrm{kBq})\end{array}$ & $\left(1-N_{c} / N_{\gamma}\right) /\left(N_{d} / N_{\gamma}\right)$ & $\begin{array}{c}N_{\beta} N_{\gamma} / N_{c} \\
(\mathrm{kBq})\end{array}$ \\
\hline 0,2385 & $11,466(28)$ & 0,2002 & $11,121(27)$ \\
\hline 0,2356 & $11,448(27)$ & 0,2012 & $11,120(27)$ \\
\hline 0,2566 & $11,503(30)$ & 0,2143 & $11,107(29)$ \\
\hline 0,2572 & $11,499(30)$ & 0,2183 & $11,152(29)$ \\
\hline 0,2864 & $11,567(30)$ & 0,2373 & $11,122(29)$ \\
\hline 0,2804 & $11,509(30)$ & 0,2422 & $11,169(29)$ \\
\hline 0,4805 & $11,715(30)$ & 0,399 & $11,107(29)$ \\
\hline 0,5068 & $11,858(32)$ & 0,4126 & $11,117(30)$ \\
\hline 0,528 & $11,894(32)$ & 0,422 & $11,065(29)$ \\
\hline 0,5477 & $11,926(32)$ & 0,4273 & $11,111(30)$ \\
\hline 0,558 & $11,904(33)$ & 0,4328 & $11,079(30)$ \\
\hline 0,5859 & $11,966(32)$ & 0,4433 & $11,121(30)$ \\
\hline 0,6086 & $11,982(32)$ & 0,4552 & $11,119(31)$ \\
\hline 0,6302 & $12,058(33)$ & 0,4739 & $11,121(30)$ \\
\hline 0,651 & $12,034(32)$ & 0,4967 & $11,148(30)$ \\
\hline 0,6735 & $12,060(33)$ & 0,5077 & $11,152(30)$ \\
\hline 0,6913 & $12,063(33)$ & 0,5213 & $11,069(30)$ \\
\hline 0,7194 & $12,098(34)$ & 0,5357 & $11,193(30)$ \\
\hline 0,7404 & $12,134(34)$ & 0,552 & $11,171(30)$ \\
\hline- & - & 0,5573 & $11,107(30)$ \\
\hline- & - & 0,5793 & $11,112(31)$ \\
\hline- & - & 0,5951 & $11,121(31)$ \\
\hline
\end{tabular}


Com os dados obtidos, pode-se obter o gráfico da FIG.4.2 onde tem-se $N_{\beta} N_{\gamma} / N_{c}$ em função de $\left(1-N_{c} / N_{\gamma}\right) /\left(N_{c} / N_{\gamma}\right)$ para os dois intervalos de energias considerados. A eficiência do detector beta variou de $81 \%$ a $57 \%$ para as medidas realizadas em gama $I$ e de $83 \%$ a $63 \%$ para as medidas realizadas em gama II. Os pontos em azul correspondem às medidas no intervalo gama $I$ e os pontos em vermelho correspondem às medidas no intervalo gama II.

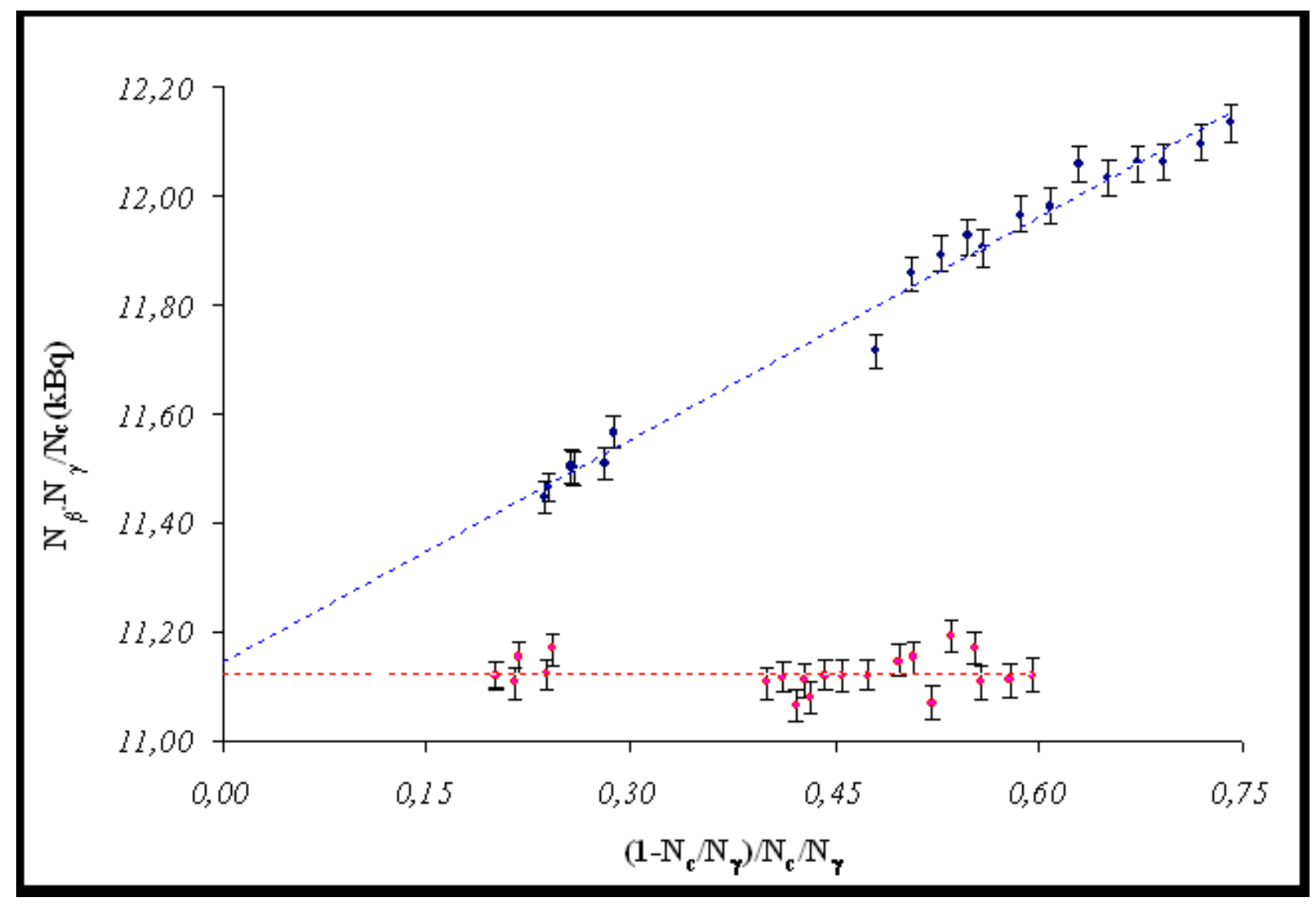

FIGURA 4.2 Curva de extrapolação para os dois intervalos de energia $\gamma$ para a fonte 2 .

Para a fonte 3 foram realizadas 11 medidas com um tempo real de 2000 segundos cada. Na TAB.4.3 são apresentados os valores da ineficiência (1$\left.N_{c} / N_{\gamma}\right) /\left(N_{c} / N_{\gamma}\right)$ e atividade obtidas $\left(N_{\beta} N_{\gamma} / N_{c}\right)$ com suas respectivas incertezas, para os dois intervalos de energia gama. 
TABELA 4.3 Variação da atividade da fonte 3 em função da variação da eficiência.

\begin{tabular}{cccc}
\hline \hline & Gama I & \multicolumn{2}{c}{ Gama II } \\
$\left(1-N_{c} / N_{\gamma}\right) /\left(N_{c} / N_{\gamma}\right)$ & $N_{\beta} N_{\gamma} / N_{c}$ & $\left(1-N_{c} / N_{\gamma}\right) /\left(N_{c} / N_{\gamma}\right)$ & $N_{\beta} \cdot N_{\gamma} / N_{c}$ \\
& $(\mathrm{kBq})$ & & $(\mathrm{kBq})$ \\
\hline \hline 0,1119 & $2,5283(61)$ & 0,0901 & $2,491(10)$ \\
0,1116 & $2,5380(61)$ & 0,0940 & $2,487(10)$ \\
0,1208 & $2,5232(63)$ & 0,0949 & $2,470(10)$ \\
0,1310 & $2,5368(63)$ & 0,0960 & $2,458(10)$ \\
0,1434 & $2,5405(64)$ & 0,1133 & $2,474(10)$ \\
0,1610 & $2,5615(67)$ & 0,1337 & $2,501(11)$ \\
0,1606 & $2,5405(66)$ & 0,1242 & $2,461(11)$ \\
0,1752 & $2,5645(67)$ & 0,1394 & $2,486(12)$ \\
0,1765 & $2,5653(67)$ & 0,1342 & $2,473(12)$ \\
0,1748 & $2,5524(69)$ & 0,1387 & $2,474(12)$ \\
0,1854 & $2,5556(69)$ & 0,1497 & $2,479(12)$ \\
\hline
\end{tabular}

Com os dados obtidos, pode-se obter o gráfico da FIG.4.3 onde tem-se $N_{\beta} N_{\gamma} / N_{c}$ em função de $\left(1-N_{C} / N_{\gamma}\right) /\left(N_{C} / N_{\gamma}\right)$ para os dois intervalos de energia considerados. A eficiência do detector beta variou de $90 \%$ a $84 \%$ para as medidas realizadas em gama $I$ e de $92 \%$ a $87 \%$ para as medidas realizadas em gama II. Os pontos em azul correspondem às medidas no intervalo gama $I$ e os pontos em vermelho correspondem às medidas no intervalo gama II. 


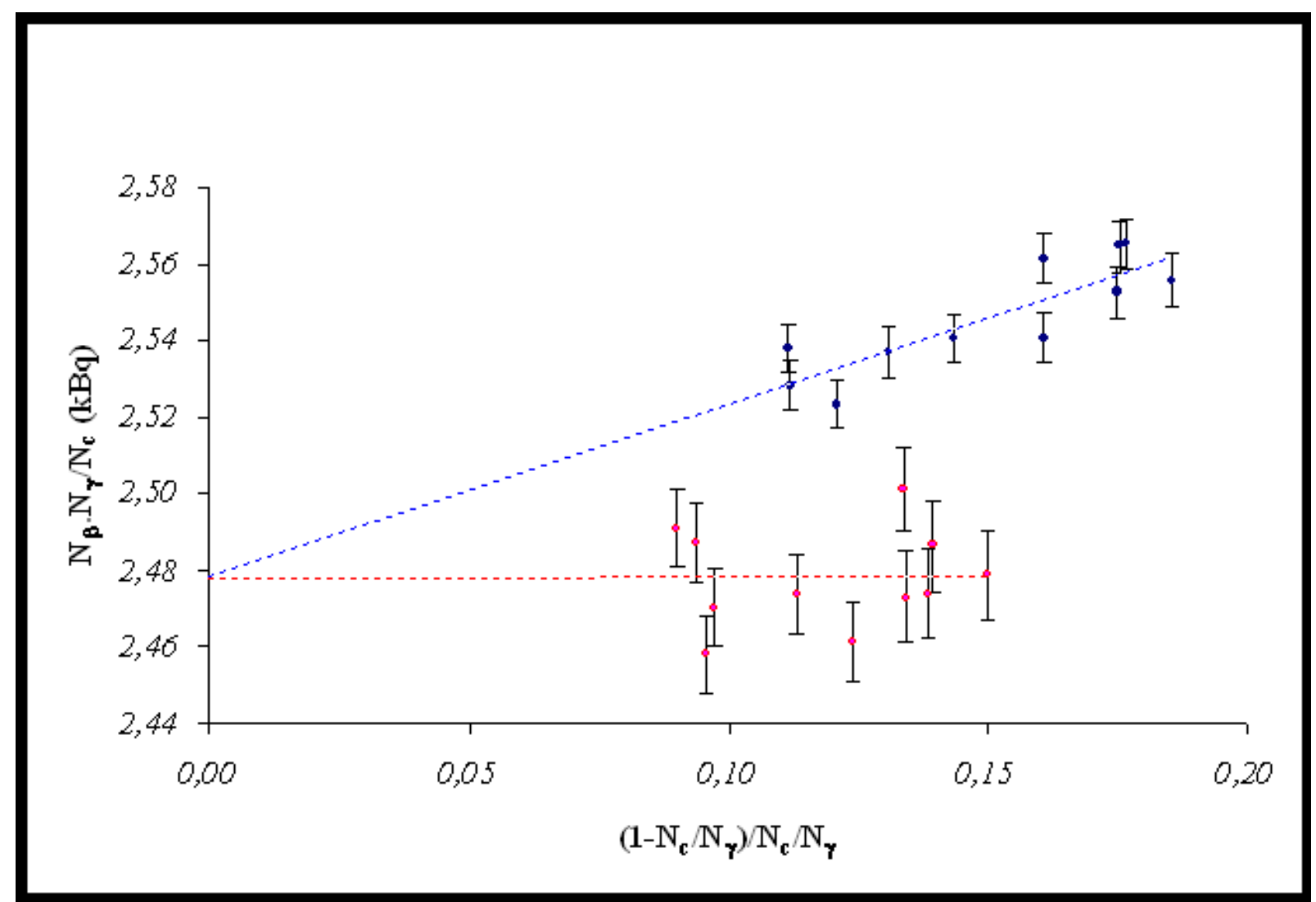

FIGURA 4.3 Curva de extrapolação para os dois intervalos de energia $\gamma$ para a fonte 3 .

Os parâmetros da curva de calibração para os dois intervalos de energia gama selecionados foram obtidos por meio do código LINFIT $^{[29]}$, que considera no ajuste a matriz de covariância das incertezas. $\mathrm{O}$ valor extrapolando fornece a atividade da fonte.

$\mathrm{Na}$ TAB.4.4 são apresentados os resultados das atividades obtidas para as três fontes nos dois intervalos de energia gama selecionados, assim como a média ponderada das atividades.

TABELA 4.4 Valores das atividades das 3 fontes nos dois intervalos de energia $\gamma$.

\section{Atividade (kBq)}

\begin{tabular}{cccc} 
Fonte & Gama I & Gama II & Média Ponderada \\
\hline \hline $\mathbf{1}$ & $2,115(10)$ & $2,113(2)$ & $2,113(2)$ \\
$\mathbf{2}$ & $11,145(28)$ & $11,123(30)$ & $11,135(20)$ \\
$\mathbf{3}$ & $2,478(14)$ & $2,477(5)$ & $2,477(5)$ \\
\hline
\end{tabular}




\subsubsection{Comparação dos resultados experimentais com a simulação de Monte Carlo}

Como pode-se observar, as atividades obtidas para os intervalos de energia selecionados para cada uma das fontes, são concordantes dentro de suas incertezas.

Para obter a atividade final prevista pela simulação de Monte Carlo, foi feita a interpolação da atividade normalizada correspondente as ineficiências experimentais, determinando-se a razão $N_{\beta} N_{\gamma} / N_{c}$ para cada ponto medido. Pela média das razões obtém-se a taxa de desintegração $\mathrm{N}_{0 \mathrm{MC}}$.

$$
\left(\frac{N_{\beta} N_{\gamma}}{N_{c}}\right)_{\exp } /\left(\frac{N_{\beta} N_{\gamma}}{N_{c}}\right)_{M C}=N_{0 M C}
$$

Os resultados apresentados nas tabelas 4.5 e 4.6 representam os valores teóricos comparados com os obtidos experimentalmente para os dois intervalos de energia gama selecionadas, gama I e II respectivamente. Na FIG.4.4 é comparada a atividade das três fontes com o valor obtido pelas simulações de Monte Carlo, as atividades foram normalizadas a 1.

TABELA 4.5 Comparação entre os valores previstos e os observados para o intervalo de energia gama $I$.

\begin{tabular}{cccc}
\hline \hline Fonte & $\begin{array}{c}\text { Experimental } \\
(\mathbf{k B q})\end{array}$ & $\begin{array}{c}\text { Monte Carlo } \\
(\mathbf{k B q})\end{array}$ & Razão \\
\hline \hline $\mathbf{1}$ & $2,115(10)$ & $2,112(2)$ & $1,001(5)$ \\
$\mathbf{2}$ & $11,145(28)$ & $10,877(20)$ & $1,025(3)$ \\
$\mathbf{3}$ & $2,478(14)$ & $2,470(4)$ & $1,003(6)$ \\
\hline
\end{tabular}


TABELA 4.6 Comparação entre os valores previstos e os observados para o intervalo de energia gama II.

\begin{tabular}{cccc}
\hline \hline Fonte & $\begin{array}{c}\text { Experimental } \\
(\mathbf{k B q})\end{array}$ & $\begin{array}{c}\text { Monte Carlo } \\
(\mathbf{k B q})\end{array}$ & Razão \\
\hline \hline $\mathbf{1}$ & $2,113(2)$ & $2,114(4)$ & $0,9995(21)$ \\
$\mathbf{2}$ & $11,123(30)$ & $11,121(17)$ & $1,0002(31)$ \\
$\mathbf{3}$ & $2,477(5)$ & $2,476(5)$ & $1,0004(29)$ \\
\hline \hline
\end{tabular}

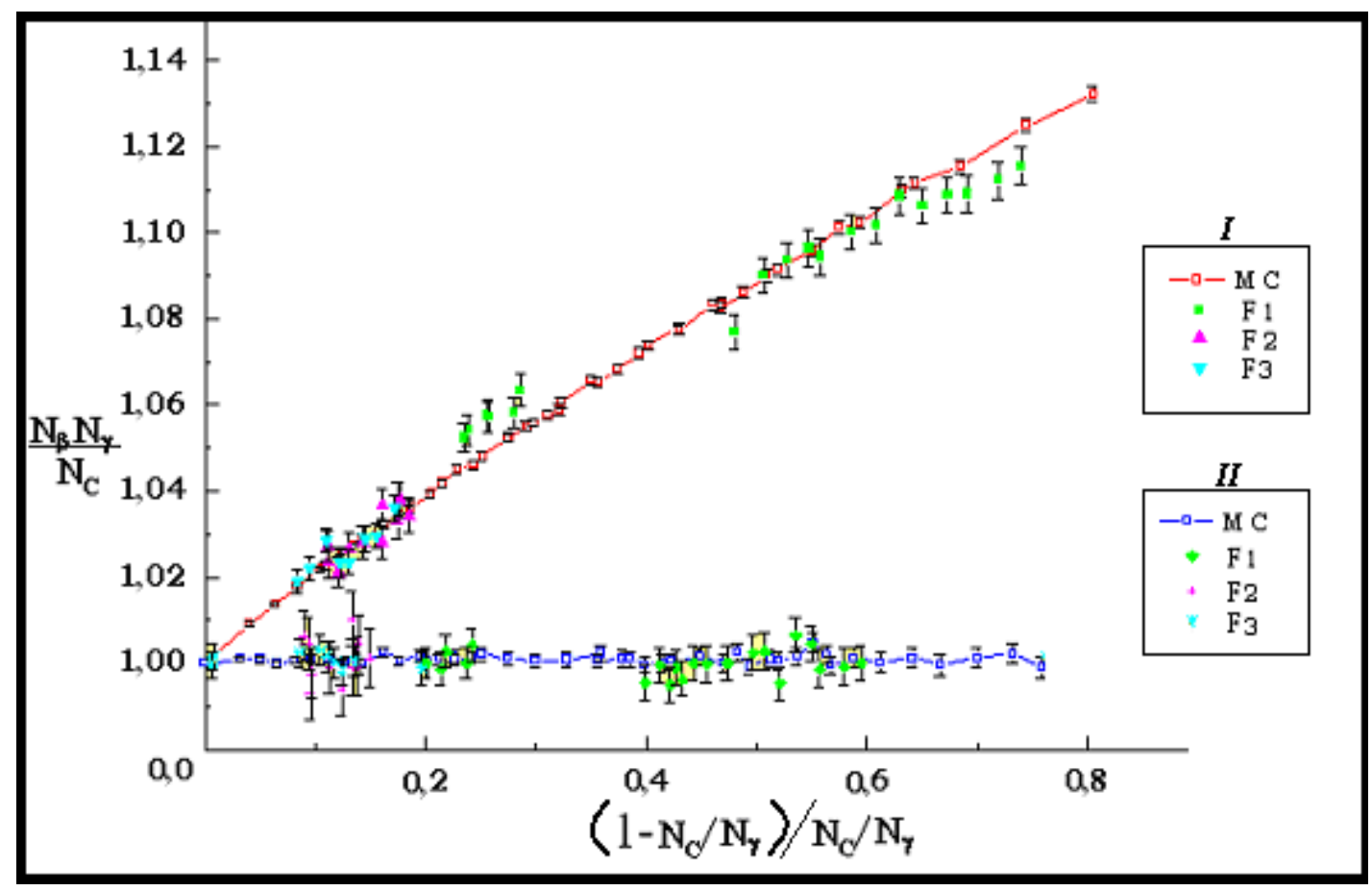

FIGURA 4.4 Curva com os valores previstos e observados normalizados.

Na FIG.4.4 a linha em vermelho representa a curva de extrapolação dada por Monte Carlo para o intervalo de energias do gama $I$, os pontos em verde, rosa e azul representam os pontos experimentais para as fonte 1, 2 e 3, respectivamente. A linha em azul representa a curva de extrapolação dado por Monte Carlo para o intervalo de energias do gama II, os pontos em verde, rosa e azul representam os pontos experimentais para as fonte 1,2 e 3 , respectivamente. 


\subsection{Determinação das probabilidades de emissão gama por decaimento}

São apresentados os resultados obtidos na determinação das probabilidades de emissão gama por decaimento do ${ }^{182} \mathrm{Ta}$ de acordo com os procedimentos descritos no capítulo 3. As medidas dos espectros foram feitas em um tempo da ordem de $10^{5}$ segundos e o tempo para as medidas de radiação de fundo da ordem de $10^{4}$ segundos.

Na TAB.4.7 são apresentados os valores das probabilidades gama das transições mais intensas obtidas das medidas realizadas com as fonte 1 e 2 .

TABELA 4.7 Valores determinados das intensidades gama para a fonte 1 e 2 .

\begin{tabular}{cccc}
\hline $\begin{array}{c}\text { Energia } \\
(\mathbf{k e V})\end{array}$ & Fonte 1 & Fonte 2 & $\begin{array}{c}\text { Média } \\
\text { Ponderada }\end{array}$ \\
\hline \hline $\mathbf{8 4 , 6 8}$ & $2,718(43)$ & $2,615(21)$ & $2,627(25)$ \\
$\mathbf{1 0 0 , 1 1}$ & $14,34(12)$ & $13,823(87)$ & $13,88(12)$ \\
$\mathbf{1 5 2 , 4 3}$ & $7,018(75)$ & $6,929(48)$ & $6,941(60)$ \\
$\mathbf{1 5 6 , 3 9}$ & $2,671(63)$ & $2,609(26)$ & $2,616(29)$ \\
$\mathbf{1 7 9 , 3 9}$ & $3,065(54)$ & $3,068(26)$ & $3,066(30)$ \\
$\mathbf{2 2 2 , 1 1}$ & $7,482(72)$ & $7,422(51)$ & $7,434(65)$ \\
$\mathbf{2 2 9 , 3 2}$ & $3,618(71)$ & $3,620(31)$ & $3,619(36)$ \\
$\mathbf{2 6 4 , 0 8}$ & $3,481(57)$ & $3,570(30)$ & $3,557(35)$ \\
$\mathbf{1 0 0 1 , 7 0}$ & $2,10(13)$ & $2,096(47)$ & $2,103(46)$ \\
$\mathbf{1 1 2 1 , 3 0}$ & $34,93(32)$ & $34,83(23)$ & $34,85(14)$ \\
$\mathbf{1 1 8 9 , 0 5}$ & $15,98(17)$ & $15,87(12)$ & $15,89(14)$ \\
$\mathbf{1 2 2 1 , 4 1}$ & $27,74(46)$ & $26,95(19)$ & $27,03(24)$ \\
$\mathbf{1 2 3 1 , 0 2}$ & $11,29(19)$ & $11,406(92)$ & $11,39(34)$ \\
$\mathbf{1 2 5 7 , 4 2}$ & $1,48(14)$ & $1,514(33)$ & $1,513(33)$ \\
\hline
\end{tabular}


Por meio do código LINFIT $^{[29]}$ foi obtida uma média que considera no ajuste a matriz de covariância das incertezas das grandezas, incertezas como a da atividade da fonte, incerteza da área de contagem da medida e incerteza da correção para o decaimento da fonte.

Na TAB.4.8 são apresentados os valores para as probabilidades gama por decaimento obtido neste trabalho comparado com os valores encontrados na literatura.

TABELA 4.8 Comparação entre os valores observados com os encontrados na literatura.

\begin{tabular}{ccccc}
\hline \hline $\begin{array}{c}\text { Energia } \\
\text { keV }\end{array}$ & Este trabalho & Data Sheets $^{[16]}$ & Firestone $^{[21]}$ & Miyahara $^{[30]}$ \\
\hline \hline $\mathbf{8 4 , 6 8}$ & $2,627(25)$ & $2,65(42)$ & $2,645(67)$ & $2,68(2)$ \\
$\mathbf{1 0 0 , 1 1}$ & $13,88(12)$ & $14,03(70)$ & $14,10(26)$ & $13,59(6)$ \\
$\mathbf{1 5 2 , 4 3}$ & $6,941(60)$ & $7,15(53)$ & $6,93(13)$ & $6,92(2)$ \\
$\mathbf{1 5 6 , 3 9}$ & $2,616(29)$ & $2,72(24)$ & $2,642(49)$ & $2,672(10)$ \\
$\mathbf{1 7 9 , 3 9}$ & $3,066(30)$ & $3,14(34)$ & $2,925(54)$ & $3,098(11)$ \\
$\mathbf{2 2 2 , 1 1}$ & $7,434(65)$ & $7,54(71)$ & $7,49(14)$ & $7,48(3)$ \\
$\mathbf{2 2 9 , 3 2}$ & $3,619(36)$ & $3,63(35)$ & $3,630(66)$ & $3,601(13)$ \\
$\mathbf{2 6 4 , 0 8}$ & $3,557(35)$ & $3,63(35)$ & $3,605(67)$ & $3,579(13)$ \\
$\mathbf{1 0 0 1 , 7 0}$ & $2,103(46)$ & $2,09(11)$ & $2,066(38)$ & $*$ \\
$\mathbf{1 1 2 1 , 3 0}$ & $34,85(14)$ & $34,9(1,7)$ & $34,90(61)$ & $35,32(12)$ \\
$\mathbf{1 1 8 9 , 0 5}$ & $15,89(14)$ & $16,40(95)$ & $16,23(28)$ & $16,49(6)$ \\
$\mathbf{1 2 2 1 , 4 1}$ & $27,03(24)$ & $27,3(13)$ & $26,98(48)$ & $27,71(9)$ \\
$\mathbf{1 2 3 1 , 0 2}$ & $11,39(34)$ & $11,55(70)$ & $11,44(20)$ & $11,72(4)$ \\
$\mathbf{1 2 5 7 , 4 2}$ & $1,513(33)$ & $1,51(10)$ & $1,488(26)$ & $1,393(7)$ \\
\hline \hline
\end{tabular}

*não encontrado na literatura. 
As probabilidades de emissão gama por decaimento determinadas neste trabalho concordam dentro da incerteza experimental em sua maioria com os valores apresentados pelo Nuclear Data Sheets ${ }^{[6]}$ e por Firestone ${ }^{[21]}$. Discorda entretanto com os valores apresentados por Miyahara ${ }^{[30]}$ que apresenta incertezas menores. 


\section{CONCLUSÕES}

No presente trabalho foi desenvolvida a metodologia de medida absoluta de atividade para o radionuclídeo ${ }^{182} \mathrm{Ta}$ no sistema de coincidência $4 \pi(\mathrm{PC})-\mathrm{NaI}(\mathrm{Tl})$ como foi proposto. A técnica de misturar em água as amostras radioativas do pó de óxido de tântalo $\left(\mathrm{Ta}_{2} \mathrm{O}_{5}\right)$ mostrou-se eficaz uma vez que a dissolução do óxido é muito trabalhosa.

Os resultados das padronizações das três fontes de ${ }^{182} \mathrm{Ta}$ utilizando dois intervalos de energias (gama $I$ e gama $I I$ ) foram concordantes dentro de suas respectivas incertezas, bem como quando comparadas com as simulações feitas por Monte Carlo com exceção do resultado do primeiro intervalo (gama $I$ ) da fonte 2 que apresentou um valor de 2,37\% acima do valor obtido teoricamente, este fato deverá ser analisado com mais detalhe.

Os resultados da determinação das probabilidades de emissão gama por decaimento estudados são concordantes dentro de suas incertezas experimentais com os valores da literatura, Data Sheets ${ }^{[16]}$ e Firestone ${ }^{[21]}$, mas discorda com alguns dos valores apresentados por Miyahara ${ }^{[30]}$ indicando que medidas confirmatórias são necessárias. Não foi possível incluir a terceira fonte na média da determinação das probabilidades de emissão gama por decaimento por razões técnicas em que o espectro gama não pode ser utilizado.

A introdução de um padrão de ${ }^{166 m}$ Ho na determinação da curva de eficiência para o sistema de espectroscopia gama permitiu o ajuste de um único polinômio no intervalo de energia de $59 \mathrm{keV}$ a $1408 \mathrm{keV}$, fato este que não foi possível verificar em estudos anteriores ${ }^{[2]}$ por falta dos pontos agora fornecidos pelo ${ }^{166 \mathrm{~m}} \mathrm{Ho}$. 
Para trabalhos futuros sugerimos a padronização de fontes de ${ }^{182}$ Ta na forma de fio metálico, uma vez que este tipo de fonte seria mais prática para os usuários do sistema de espectroscopia gama.

Este tipo de fonte apresenta baixa eficiência beta ocasionada pela auto-absorção na fonte, o uso do programa de simulação se torna muito útil, como auxiliar na determinação da correção para atividade da fonte em forma de fio, por isso sugerimos a aplicação do programa de simulação para a região de baixa eficiência. 


\section{REFERÊNCIAS}

[1] HILÁRIO, K., A, F. - Desenvolvimento de métodos de medida da atividade empregando sistemas de coincidência para radionuclídeos que desintegram pela dupla emissão $\beta^{-}$e $\beta^{+} /$captura eletrônica - aplicação na padronização do ${ }^{192} I r,{ }^{152} \mathrm{Eu}$ $\boldsymbol{e}^{186} \boldsymbol{R} \boldsymbol{e}$. Tese de doutoramento, Universidade de São Paulo, São Paulo, 2002.

[2] MOREIRA, D., S. - Padronização dos radionuclídeos multi-emissores gama ${ }^{166 m}{ }^{H o}$ e ${ }^{72}$ Ga e determinação de suas intensidades gama por decaimento. Tese de doutoramento, Universidade de São Paulo, São Paulo, 2005.

[3] EISBERG, R., RESNICK, R. - Física Quântica. Átomos, Moléculas, Sólidos Núcleos e Partículas., 5ed., Campus, Rio de Janeiro, 2002.

[4] BEISER, A. - Conceitos de Física Moderna., 1.ed., Edusp, São Paulo, 1969.

[5] CHUNG, K.C. - Introdução à Física Nuclear., EDURJ, Rio de Janeiro, 2001.

[6] KNOLL, G. F. - Radiation Detection and Measurement. 2. ed., John Wiley \& Sons, New York, 1989.

[7] BAERG, A. P. Absolute measurament of radioatctivity. - Metrologia. $\underline{3}$, n. 4, p. 105-108, 1967. 
[8] CAMPION, P.J. The standardization of radioisotopes by the beta-gamma coincidence method using high efficiency detectors. Int. J. Appl. Radiat. Iso.E.U.A. $\underline{4}$, p: 232-248, 1959.

[9] BAERG, A. P. The efficiency extrapolation method in coincidence counting.Nuclear Instruments Method. 112, 143-150 E.U.A.: 1973.

[10] MOURA, L.P. - Método de coincidência generalizado para a medida absoluta da atividade de radionuclídeos - Aplicação na determinação do coeficiente de conversão interna da transição de $279 \mathrm{keV}$ do 203Tl., Tese de doutoramento, Universidade Estadual de Campinas, 1969.

[11] ZEVALLOS-CHÁVES, J.Y.- Função Resposta de Detectores Semicondutores Ge e Si(Li), Tese de doutoramento, IFUSP, São Paulo, 2003.

[12] PIRES, C. A. - Calibração em eficiência de detectores de Ge com o auxílio do código EGS., Trabalho de conclusão de curso, universidade de Santo Amaro, São Paulo, 2004.

[13] KRANE, K. S. - Introductory Nuclear Physics., 2ed., John Wiley \& Sons, New York, 1988.

[14] KOSKINAS, M. F., DA SILVA, E. A., YAMAZAKI, I., M., DIAS, M. S. Standardization of ${ }^{241} \mathrm{Am}$ Solution. Applied radiation and isotopes., 64, p. 12381241, (2006).

[15] DIAS, M. S., 1999. - CONTAC- Relatorio interno, IPEN-CNEN/SP.

[16] SCHOMARAK, M. R. - Nuclear Data Sheets., volume 14, n4 april of 1975. 
[17] COX, D.R, and ISHAM, V., A bivariate point process connected with eletronic counters. Proceedings of the Royal Society of London, A, 356, p. 149-160,1977.

[18] SMITH, D.L., Some developments ins the Cox-Isham theory to coicidence corrections, including the extension to the computer-discrimination method.. Applied Radition Isotopes, $\underline{38}$ (10), p.813-822,1987.

[19] Neutron scattering lengths and cross sections. Disponível em:

$<$ http://www.ncnr.nist.gov/resources/n-lengths/elements/ta.html $>$ Acesso em: 27 set. 2006.

[20] PENTEADO FILHO, A. C. - Irradiação no Reator e cálculos de ativação. Informação IEA No23, São Paulo, novembro de 1972.

[21] FIRESTONE, R. B. - Table of Isotope CD-ROM., Eighth edition, version 1.0, New York, march 1996.

[22] TAKEDA, M.N. - Aplicação do método de Monte Carlo no estudo da padronização de radionuclídeos com esquema de desintegração complexo em sistema de coincidência $4 \pi \beta-\gamma$., Tese de doutoramento, Universidade de São Paulo, São Paulo, 2006.

[23] ORNL, Monte Carlo N-Particle Transport Code System, MCNP4C, RSICC Computer codecollection, Oak Ridge National Laboratory. Report CCC-700, 2001.

[24] Germanium detectors- User's manual, Camberra Industries, copyright 1993. 
[25] TAKEDA, M.N. - Determinação da correção para o efeito de soma em cascata para o espectrômetro de HPGe pelo método de Monte Carlo., Dissertação de Mestrado, Universidade de São Paulo, São Paulo, 2001.

[26] International Atomic Energy Agency. X-ray and gamma-ray standards for detector calibration, IAEA-TCDOC-619,1991.

[27] DIAS, M. S. - ALPINO. Código para cálculo da eficiência e atividade de um espectrômetro de raios gama em HPGe. Laboratório de Metrologia Nuclear, IPEN, Relatório interno, 2002.

[28] DIAS, M. S., 1999-LOGFIT- Relatório interno, IPEN-CNEN/SP.

[29] Dias, M.S., 1999. LINFIT: a code for linear least square fit with covariance analysis. Internal Report, IPEN-CNEN/SP.

[30] MIYAHARA, H; NAGATA, H; FURUSAWA, T; MURAKAMI, N; MORI, C; TAKEUCHI, N; GENKA, T., Gamma-ray Emission Probabilities of ${ }^{182}$ Ta. - Applied Radiation Isotopes. 49, №. 9-11, pp 1383-1386, 1998. 